\title{
Asset Pricing Tests with Long Run Risks in Consumption Growth
}

By

George M. Constantinides

Anisha Ghosh

DISCUSSION PAPER NO 609

DISCUSSION PAPER SERIES

February 2008

George M. Constantinides is a Leo Melamed Professor of Finance at Graduate School of Business, University of Chicago and a research associate at the National Bureau of Economic Research. He received a bachelor's degree in 1970 and a master's degree in 1974 from Oxford University. He earned an MBA in 1972 and a DBA in 1975 both from Indiana University. He joined the GSB faculty in 1979, having previously taught at Carnegie Mellon University. He also visited Harvard University as a Marvin Bower Fellow in 1985-86. Anisha Ghosh is a PhD student in the Department of Economics at London School of Economics and Political Science. She completed her BSc in Economics from Presidency College, Calcutta in 2003 and then the MRes in Economics at London School of Economics and Political Science in 2005. Any opinions expressed here are those of the authors and not necessarily those of the FMG. The research findings reported in this paper are the result of the independent research of the authors and do not necessarily reflect the views of the LSE. 


\title{
Asset Pricing Tests with Long Run Risks in Consumption Growth*
}

\author{
George M. Constantinides ${ }^{\dagger} \quad$ Anisha Ghosh ${ }^{\ddagger}$ \\ this version: February 28, 2008
}

\begin{abstract}
The Bansal and Yaron (2004) model of long run risks (LLR) in aggregate consumption and dividend growth and its extension that captures potential cointegration of the consumption and dividend levels, are tested on a cross-section of asset classes and rejected using annual data over the period 1930-2006 and using both annual and quarterly data over the post-war period. The reversal of earlier empirical conclusions is partly due to the increase in the power of the tests resulting from two observations under the null. First, the latent state variables and, therefore, the pricing kernel are known affine functions of observables such as the interest rate and the market-wide price-dividend ratio. Second, the parameters of the time-series processes of consumption and dividend growth, the LLR variable, and its conditional variance impose constraints on the parameters of the pricing kernel. The value of the persistence parameter of the LRR variable that best fits the data implies that its half-life is shorter than that of the business cycle.

Keywords: Long Run Risks, Equity Premium, Cross-Section of Asset Returns, Cointegration, Latent State Variables.

JEL classification: G12, E44
\end{abstract}

*We thank John Campbell, Eugene Fama, Lars Hansen, Christian Julliard, Oliver Linton, Sydney Ludvigson, Lubos Pastor, Annette Vissing-Jorgensen, and, in particular, John Cochrane for helpful comments. We remain responsible for errors and omissions. Constantinides acknowledges financial support from the Center for Research in Securities Prices of the University of Chicago. Ghosh acknowledges financial support from the London School of Economics.

${ }^{\dagger}$ Graduate School of Business, University of Chicago and NBER, email: gmc@chicagogsb.edu

‡Department of Economics, London School of Economics, e-mail: a.ghosh@lse.ac.uk 


\section{Introduction}

Whereas the neoclassical economic model parsimoniously links the returns of all assets to per capita consumption growth through the Euler equations of consumption, per capita consumption growth covaries too little with the returns of most classes of financial assets and this creates a host of asset pricing puzzles: the aggregate equity return and the returns of various subclasses of financial assets are too large, too variable, and too predictable. Several generalizations of essential features of the model have been proposed to mitigate its poor performance. ${ }^{1}$

In particular, Bansal and Yaron (2004) introduce a "long-run risks" (LRR) state variable that simultaneously drives aggregate consumption growth and aggregate dividend growth. In conjunction with Kreps and Porteus (1978) preferences, the LRR state variable has a rich set of pricing implications and shows promise in explaining the cross-section of expected returns of various classes of financial assets ${ }^{2}$.

The first contribution of our paper is to re-examine the empirical evidence on the LRR model. Unlike Bansal and Yaron (2004) and Bansal, Kiku, and Yaron (2007) who treat the LRR variable and the conditional variance of its innovation as latent state variables, we argue that these state variables are observable because both the aggregate price-dividend ratio and interest rate are functions only of these two state variables under the model assumptions. In the particularly simple log-linearized version of the model, the aggregate price-dividend ratio and interest rate are affine functions of the two state variables, with coefficients that are known functions of the preference parameters and of the parameters of the time-series processes. This observation allows us to invert the affine system and express the two state variables as known affine functions of the observable aggregate price-dividend ratio and interest rate. Therefore, we are able to express the pricing kernel as an affine function of the aggregate pricedividend ratio, interest rate, and their lags.

In GMM tests at the annual frequency over 1930-2006, we strongly reject the hypothesis that the above pricing kernel explains the equity premium when we impose the constraint that the estimated parameters should be consistent with the parameters that drive the time-series processes of consumption growth, aggregate dividend growth, the LRR variable, and the conditional variance of its innovation. We marginally reject the hypothesis that it explains the value and size premia when we do not impose the

\footnotetext{
${ }^{1}$ This extensive literature is reviewed in a collection of essays in Mehra (2008); the textbooks by Campbell, Lo, and MacKinlay (1997) and Cochrane (2005); and the articles by Campbell $(2000,2003)$, Cochrane and Hansen (1992), Constantinides (2002), Kocherlakota (1996), and Mehra and Prescott (2003).

${ }^{2}$ See also, Alvarez and Jerman (2005), Bansal, Dittmar, and Lundblad (2005), Bansal, Gallant, and Tauchen (2007), Bansal, Kiku, and Yaron (2007), Bekaert, Engstrom, and Xing (2005), Hansen, Heaton, and Li (2006), Hansen and Scheinkman (2007), Kiku (2006), Lettau and Ludvigson (2005), and Malloy, Moskowitz, and Vissing-Jorgensen (2004).
} 
constraint; however, we strongly reject the hypothesis that it explains the value and size premia when we impose the constraint.

The reversal of earlier conclusions by Bansal and Yaron (2004) and Bansal, Kiku, and Yaron (2007) is due, in part, to the increased power of the tests brought about by the recognition that the state variables, LRR and the conditional variance of its innovation, are not latent after all but that the pricing kernel is an affine function of the aggregate price-dividend ratio and interest rate; and the added restriction that the estimated parameters should be consistent with the parameters that drive the timeseries processes of consumption growth, aggregate dividend growth, the LRR variable, and the conditional variance of its innovation.

Recent research reports evidence of structural breaks in the equity premium (Pastor and Stambaugh (2001)) and in the mean of the log dividend-price ratio of the market (Lettau and Van Nieuwerburgh (2007)) in the post-war period. Hence, rejection of the LRR model may be due to failure to account for a post-war regime shift. We explore this possibility by repeating the tests over the post-war period. We find that the model performs considerably better. We still reject the hypothesis that the model explains the cross-section of returns, when we choose the value of the persistence parameter of the LRR variable to make the half-life of the LRR variable longer than that of the business cycle. However, we only marginally reject the model when we search for the value of the persistence parameter of the LRR variable that best fits the data. This value is 0.5 , implying that the half-life of the $L R R$ variable is one year, much shorter than that of the business cycle and of most state variables put forth in the asset pricing literature. Using quarterly data over the post-war period leads to similar conclusions. These results raise the possibility that the shift in the mean growth rate of consumption and dividends may be of higher frequency than what has been previously emphasized in the literature.

The second contribution of our paper is to re-examine the empirical evidence of an extended version of the model that introduces as a third state variable the cointegrating residual of the logarithms of consumption and aggregate dividend levels. Such a co-integrating relationship has been introduced in the LRR model by Bansal, Dittmar, and Kiku (2007) and Bansal, Gallant, and Tauchen (2007). A simple extension of our earlier observation is that the aggregate price-dividend ratio and the interest rate are affine functions of the three state variables, with coefficients that are known functions of the preference parameters and of the parameters of the time-series processes. As before, this allows us to express the pricing kernel as an affine function of the aggregate price-dividend ratio, the interest rate, the demeaned aggregate dividend-consumption ratio, and their lags.

In GMM tests at the annual frequency over 1930-2006, we, once again, reject the hypothesis that the above pricing kernel explains the equity premium and the hypothesis that it explains the value and size premia, when we impose the constraint that the estimated parameters should be consistent with the parameters that drive 
the time-series processes of consumption growth, aggregate dividend growth, the LRR variable, and the conditional variance of its innovation. The performance of the model improves in annual and quarterly data in the post-war period 1947:2-2003:3, although the specification is still rejected.

Finally, note that the methodology of expressing latent state variables as known functions of observables has been previously employed in testing affine models of the term structure of interest rates (see, Dai and Singleton (2000)). In these models, bond yields are affine functions of the latent state variables. Hence, the system may be inverted to express the state variables as affine functions of the observable yields. To our knowledge, our paper is the first application of this methodology in testing models of the cross section of equity returns. The same approach may be applied to evaluate the empirical plausibility of other asset pricing models, like the external habit model of Menzly, Santos, and Veronesi (2004).

The paper is organized as follows. In Section 2, we describe our estimation methodology of the Bansal and Yaron (2004) LRR model. In Section 3, we discuss the data. Section 4 discusses the estimation results and, hence, the empirical evidence on the LRR model for the market portfolio and the risk free rate. Section 5 examines the ability of the model to explain the cross section of asset returns. In Section 6, we estimate the time-series parameters of the model and simulate the model to examine the finite-sample performance of the GMM statistics. Section 7 discusses some additional diagnostics of the model based on the constraints imposed by the parameters, that drive the time-series processes of consumption growth, aggregate dividend growth, the LRR variable, and the conditional variance of its innovation, on the parameters of the pricing kernel. In Section 8, we consider an extension of the LRR model that introduces, as a third state variable, the co-integrating residual of the logarithms of consumption and aggregate dividend levels and discuss the extension of the estimation methodology proposed in Section 2 to this extended model. Section 9 presents estimation results for the extended specification. In the concluding Section 10, we discuss extensions of the model and work in progress. The appendix contains the details of the estimation methodology for the Bansal and Yaron (2004) model and its extension that captures potential cointegration.

\section{Estimation Methodology}

The Bansal and Yaron (2004) LRR model relies on the Kreps and Porteus (1978) preferences that allow for separation between the intertemporal elasticity of substitution and risk aversion. The aggregate consumption and dividend growth rates are modeled as containing a small persistent expected growth rate component, the long run risk, $x_{t}$, and fluctuating volatility, $\sigma_{t}$, that captures time-varying economic uncertainty: 


$$
\begin{aligned}
x_{t+1} & =\rho x_{t}+\psi \sigma_{t} e_{t+1} \\
\sigma_{t+1}^{2} & =\sigma^{2}+v\left(\sigma_{t}^{2}-\sigma^{2}\right)+\sigma_{w} w_{t+1} \\
\Delta c_{t+1} & =\mu+x_{t}+\sigma_{t} \eta_{t+1} \\
\Delta d_{t+1} & =\mu_{d}+\phi x_{t}+\varphi \sigma_{t} u_{t+1}
\end{aligned}
$$

The shocks $\eta_{t+1}, e_{t+1}, w_{t+1}, u_{t+1}$ are assumed to be i.i.d. $N(0,1)$ and mutually independent.

Epstein and Zin (1989) and Weil (1989)) show that, for any asset $j$, the first-order conditions of a representative agent's utility maximization yield the following Euler equations,

$$
\begin{gathered}
E_{t}\left[\exp \left(m_{t+1}+r_{j, t+1}\right)\right]=1 \\
m_{t+1}=\theta \log \delta-\frac{\theta}{\psi} \Delta c_{t+1}+(\theta-1) r_{c, t+1}
\end{gathered}
$$

where $m_{t+1}$ is the natural logarithm of the intertemporal marginal rate of substitution, $r_{j, t+1}$ is the $\log$ of the gross return on asset $j$, and $r_{c, t+1}$ is the unobservable log gross return on an asset that delivers aggregate consumption as its dividend each period.

Relying on log-linear approximations for the continuous return on the consumption claim, $r_{c, t+1}$, and that on the market portfolio (the return on the aggregate dividend claim), $r_{m, t+1}$, as in Campbell and Shiller (1988),

$$
\begin{aligned}
r_{c, t+1} & =\kappa_{0}+\kappa_{1} z_{t+1}-z_{t}+\Delta c_{t+1} \\
r_{m, t+1} & =\kappa_{0, m}+\kappa_{1, m} z_{m, t+1}-z_{m, t}+\Delta d_{m, t+1}
\end{aligned}
$$

where $z_{t}$ is the $\log$ price-consumption ratio and $z_{m, t}$ the $\log$ price-dividend ratio, for this model specification, Bansal and Yaron (2004) show that $z_{t}$ and $z_{m, t}$, are affine functions of the state variables, $x_{t}$ and $\sigma_{t}^{2}$,

$$
\begin{aligned}
z_{t} & =A_{0}+A_{1} x_{t}+A_{2} \sigma_{t}^{2} \\
z_{m, t} & =A_{0, m}+A_{1, m} x_{t}+A_{2, m} \sigma_{t}^{2}
\end{aligned}
$$

where the coefficients $A_{0}, A_{1}, A_{2}, A_{0, m}, A_{1, m}$, and $A_{2, m}$ depend on the parameters of the utility function and those of the stochastic processes for consumption and dividend growth rates, as given by equation (1) (see A.1.1 for expressions for $A_{0}, A_{1}, A_{2}, A_{0, m}$, $A_{1, m}$, and $\left.A_{2, m}\right)$.

Also, in this model, the risk free rate from period $t$ to $t+1$ may be expressed as an affine function of the state variables (see Appendix A.1.1 for expressions for $A_{0, f}$, $A_{1, f}$, and $\left.A_{2, f}\right)$, 


$$
\begin{aligned}
r_{f, t} & =-\log E_{t}\left[\exp \left(m_{t+1}\right)\right] \\
& =A_{0, f}+A_{1, f} x_{t}+A_{2, f} \sigma_{t}^{2}
\end{aligned}
$$

Equations (7) and (8) express the observable variables, $z_{m, t}$ and $r_{f, t}$, as affine functions of the latent state variables, $x_{t}$ and $\sigma_{t}^{2}$. These may be inverted to express the unobservable state variables, $x_{t}$ and $\sigma_{t}^{2}$, in terms of the observables, $z_{m, t}$ and $r_{f, t}$, (see Appendix A.1.2 for details),

$$
\begin{aligned}
x_{t} & =\alpha_{0}+\alpha_{1} r_{f, t}+\alpha_{2} z_{m, t} \\
\sigma_{t}^{2} & =\beta_{0}+\beta_{1} r_{f, t}+\beta_{2} z_{m, t}
\end{aligned}
$$

Now, substituting the log-affine approximation for $r_{c, t+1}$ (equation (4)), noting that $z_{t}$ is given by equation (6), into the expression for the pricing kernel (equation (3)), we have

$$
\begin{aligned}
m_{t+1}= & \left(\theta \log \delta+(\theta-1)\left[\kappa_{0}+\left(\kappa_{1}-1\right) A_{0}\right]\right)+\left(-\frac{\theta}{\psi}+(\theta-1)\right) \Delta c_{t+1} \\
& +(\theta-1) \kappa_{1} A_{1} x_{t+1}+(\theta-1) \kappa_{1} A_{2} \sigma_{t+1}^{2}-(\theta-1) A_{1} x_{t}-(\theta-1) A_{2} \sigma_{t}^{2}
\end{aligned}
$$

Substituting the expressions for $x_{t}$ and $\sigma_{t}^{2}$ from equations (9) and (10) into the pricing kernel, equation (11), we have

$$
\begin{aligned}
m_{t+1} & =c_{1}+c_{2} \Delta c_{t+1}+c_{3} r_{f, t+1}+c_{4} z_{m, t+1}+c_{5} r_{f, t}+c_{6} z_{m, t} \\
& \approx c_{1}+c_{2} \Delta c_{t+1}+c_{3}\left(r_{f, t+1}-r_{f, t}\right)+c_{4}\left(z_{m, t+1}-z_{m, t}\right)
\end{aligned}
$$

since $c_{3}=-\kappa_{1} c_{5}, c_{4}=-\kappa_{1} c_{6}$, and $\kappa_{1} \approx 1$ (see Appendix A.1.3 for details). The above expression for the pricing kernel is entirely in terms of observables. We estimate the parameters $c=\left(c_{1}, c_{2}, c_{3}, c_{4}\right)^{\prime}$ by the GMM method of Hansen (1982), using the moment conditions (2) for a set of logarithmic portfolio returns, $\left\{r_{1, t+1}, \ldots, r_{n, t+1}\right\}_{t=1}^{T}$, and also test the over-identifying restrictions.

\section{Data}

We first estimate the model at the annual frequency, using annual data over the sample period 1930 to 2006. We also repeat our analysis over the post-war period 19472003, using both annual and quarterly data. The asset menu consists of the market, 
the risk free rate, and portfolios of "Value", "Growth", "Small" capitalization, and "Large" capitalization stocks. Our market proxy is the Centre for Research in Security Prices (CRSP) value-weighted index of all stocks on the NYSE, AMEX, and NASDAQ. The proxy for the risk free rate is the one-month Treasury Bill rate (from Ibbotson Associates). The construction of the size and book-to-market portfolios is as in Fama and French (1993). In particular, for the size sort, all NYSE, AMEX, and NASDAQ stocks are allocated across 10 portfolios according to their market capitalization at the end of June of each year. Value-weighted returns on these portfolios are then computed over the following twelve months. NYSE breakpoints are used in the sort. "Small" and "Large" denote the bottom and top market capitalization deciles, respectively. Similarly, value-weighted returns are computed for portfolios formed on the basis of $\mathrm{BE} / \mathrm{ME}$ at the end of June of each year using NYSE breakpoints. The BE used in June of year $t$ is the book equity for the last fiscal year end in $t-1$ and $\mathrm{ME}$ is the price times shares outstanding at the end of December of $t-1$. "Growth" and "Value" denote the bottom and top BE/ME deciles, respectively. Annual and quarterly returns for the above portfolios are computed by compounding monthly returns within each year and quarter, respectively. Also used in the empirical analysis are the price-dividend ratio and dividend growth rates of the above mentioned portfolios. Data on these are obtained from the CRSP files. All nominal quantities are converted to real, using the personal consumption deflator.

Table 1 provides descriptive statistics for the continuously compounded returns, the price-dividend ratios, and the dividend growth rates on the six assets mentioned above, for the annual sample over the period 1930-2006. The table illustrates the well known equity premium and the size and value premia. Over the sample period, the annual equity premium over the 1-month Treasury bill rate has mean $6.3 \%$ and standard error 19.0\%. The annual risk free rate has mean $0.7 \%$ and standard deviation $5.5 \%$. The annual mean premium of small over large stocks is $3 \%$ and of value over growth stocks is $4.7 \%$. Value stocks are much more volatile than growth stocks and small stocks are much more volatile than large stocks.

The annual log price-dividend ratio on the market has a mean of 3.27 and standard error of 0.39 over the sample period. The price-dividend ratios of the "Small" and "Value" portfolios are much more volatile at 0.69 and 1.12, respectively, compared to their counterparts, namely the "Large" and "Growth" portfolios that have volatilities 0.44 and 0.63 , respectively.

The average annual log dividend growth rate on the market portfolio is $2.1 \%$ with volatility $12.7 \%$. The mean and volatility of the "Small" (8.4\% and 34.9\%) and "Value" $(8.7 \%$ and $55.2 \%)$ portfolios are much higher compared to their counterparts, namely the "Large" (1.0\% and 13.0\%) and "Growth" (1.1\% and 20.5\%) portfolios.

Finally, for consumption, we use real per capita consumption of non-durables and services from the National Income and Product Accounts (NIPA). We make the standard "end-of-period" timing assumption that consumption during period t takes place 
at the end of the period. Growth rates are constructed by taking the first difference of the corresponding log series. The annual log consumption growth has a mean of $1.5 \%$ and standard deviation of $2.6 \%$ over the sample period.

\section{Empirical Evidence on the Equity Premium}

We estimate the Euler equations (2) on annual data when the asset menu consists of the market portfolio and the risk free rate. The Bansal and Yaron (2004) model was originally intended to explain the equity premium and the low risk free rate and it seems appropriate to start the empirical analysis by examining the ability of the model to explain the returns on these two assets. The lagged log price-dividend ratio of the market and the lagged log risk free rate are used as instruments. In Table 2, Panels A, and B, we present results for the identity and efficient weighting matrices, respectively, for the sample period 1930-2006. Panel A reveals that the constant and the coefficients on consumption growth and the first difference of the risk free rate in the pricing kernel (equation (11)) are not statistically significantly different from zero, whereas the coefficient on the first difference of the price-dividend ratio of the market is significantly negative. The average pricing errors for the market and the risk free rate are small at $0.04 \%$ and $-0.24 \%$, respectively, and insignificantly different from zero. The asymptotic distribution of the J-stat is nonstandard for any positive definite weighting matrix other than the efficient weighting matrix. However, the $p$-values of the computed statistic can still be consistently computed to test the null hypothesis that the stochastic discount factor is correctly specified (see Jagannathan and Wang (1996) and Parker and Julliard (2005) for derivations of the asymptotic distribution and computation of the $p$-values when the moment conditions are linear and nonlinear, respectively, in the parameters). The critical values at the end of Table 2 reveal that the model is not rejected even at the $10 \%$ level.

The results in Panel B are largely similar except that the coefficient on the first difference of the risk free rate in the pricing kernel becomes significant as well. For this choice of the weighting matrix, the J-stat has an asymptotic $\chi^{2}$ distribution with two degrees of freedom. The computed statistic has a $p$-value of $71 \%$. The non-rejection of the pricing restrictions are confirmed using the finite-sample distribution of the J-stats obtained through Monte-Carlo simulations (see Section 6 for details of the simulation).

The tests in Table 2 focus exclusively on the pricing restrictions imposed by the model without imposing the constraint that the estimated parameters of the stochastic discount factor should be consistent with the parameters that drive the time-series processes of consumption growth, aggregate dividend growth, the LRR variable, and the variance of its innovation. Hence, non-rejection of the model specification in Table

2 does not necessarily imply support for the risk channels highlighted in the model, the low frequency movements and time-varying uncertainty in aggregate consumption and 
dividend growth rates. The above specification of the log of the stochastic discount factor as an affine function of the log consumption growth, the log price-dividend ratio of the market and the log risk free rate could arise from other asset pricing models which have two latent state variables quite unrelated to long run risks in consumption growth and fluctuating volatility.

A full test of the LRR model should incorporate restrictions imposed by the assumed preferences of the representative agent and the time-series processes (1) on the parameters of the pricing kernel. Appendix A.1 provides expressions for the parameters of the pricing kernel in terms of the underlying preference and time-series parameters. Hence, calibrated values of the time-series parameters along with plausible values for the preference parameters may be used to compute the values of the parameters of the pricing kernel. The latter may be interpreted as the values of these parameters predicted by the time-series specification of the LRR model.

We calibrate the model at the annual frequency, such that its growth rates of consumption and dividends match salient features of observed annual data. The details of the calibration are given in Section 6 and Appendix A.2. This procedure yields values for the parameters of the pricing kernel, reported in each Panel of Table 2 as "predicted" values. Note that the coefficient on the first difference of the log risk free rate predicted by the model is -146.0 , which is outside the $95 \%$ confidence interval of the same parameter estimated without the imposition of the restrictions for both choices of weighting matrices. Finally, the J-stats computed at the calibrated values of the time-series and preference parameters, for the identity and efficient weighting matrices, have p-values smaller than $1 \%$, using both the asymptotic and finite-sample distribution, the latter being obtained through simulation.

Thus, although the pricing restrictions imposed by the model are not rejected when we do not impose time-series restrictions on the processes of consumption growth, aggregate dividend growth, the LRR variable, and the variance of its innovation, imposition of the latter restrictions provides strong evidence against the model. This issue is formally addressed in Section 7.

In Table 3, we present estimation results, for the same set of assets and choice of instruments, over the post-war period 1947-2003. The period prior to 1947 was one of great economic uncertainty, including events like the Great Depression and World War II. Recent research reports evidence of structural breaks in the equity premium (Pastor and Stambaugh (2001)) and in the mean of the log dividend-price ratio of the market (Lettau and Van Nieuwerburgh (2007)) in the post-war period. Hence, rejection of the LRR model may be due to its poor performance in the pre-war period. Table 3 reports results for the identity weighting matrix. Results for the efficient weighting matrix are omitted because of its well known poor finite-sample performance for small sample sizes. Table 3 reveals that the pricing restrictions of the LRR model are not rejected, similar to Table 2, over the subsample. However, imposition of the time-series restrictions, once again, leads to a strong rejection of the model with the computed 
J-stat, at the calibrated time-series and preference parameter values, being 49.21 with a p-value smaller than $1 \%$.

In order to assess whether the rejection of the LRR model in Tables 2 and 3 is due to the effects of the decision interval and time averaging, Table 4 reports estimation results for the same set of assets and choice of instruments using quarterly data over the period 1947:2-2003:3. Panel A reveals that the coefficient on the first difference of the price-dividend ratio of the market is significant at the $10 \%$ level of significance and the overidentifying restrictions test rejects the model at significance levels smaller than 1\%. The specification is not rejected in Panel B where the J-stat has a p-value of $21.5 \%$. However, imposition of the time-series restrictions on the parameters of the pricing kernel reveals that the predicted coefficient of the first difference of the risk free rate, -43.62 , is outside the one standard error interval of the estimated value, both in Panels A and B. Also, the predicted coefficient of the first difference of the price-dividend ratio of the market, 1.467 , is outside the $95 \%$ confidend interval of the estimated value in Panel A. Moreover, the J-stats at the predicted values are 434.7 and 41.80, respectively, for the identity and the efficient weighting matrices, and both have p-values smaller than $1 \%$.

\section{Empirical Evidence on the Cross-Section}

We next explore the ability of the LRR model to explain the cross-section of annual asset returns. We estimate the Euler equations (2) when the asset menu consists of the market portfolio, the risk free rate, and the "Small", "Large", "Growth", and "Value" portfolios. In Table 5, Panels A, B, and C, we report results for the identity, efficient, and Hansen-Jagannathan weighting matrices, respectively. The constant and the coefficients on consumption growth and the first difference of the risk free rate in the pricing kernel (equation (11)) are not statistically significantly different from zero in all panels. The coefficient on the first difference of the price-dividend ratio of the market is significantly negative in Panels B and C. The J-stats in Panels A and B, but not in Panel $\mathrm{C}$, along with the critical values at the end of Table 4, reveal that the model is rejected at the $3 \%$ level.

As an additional robustness check, in Table 6, we report estimates using the same set of assets as in Table 5 but using the difference in the log price-dividend ratios of the "Value" and "Growth" portfolios, $z_{v-g, t}$, (instead of the risk free rate), and the log price-dividend ratio of the market, $z_{m, t}$, to express the unobservable state variables, $x_{t}$ and $\sigma_{t}^{2}$, as affine functions of the observables, $z_{v-g, t}$ and $z_{m, t}$. This approach is valid under the assumption that the dividend growth processes of the "Growth" and "Value" portfolios are similar to that for the market. Under this assumption, similar calculations, as in Section 2, yield that the log price-dividend ratios of these portfolios are affine functions of the state variables and, hence, so is their difference. Table 5 
reveals that the model is rejected at the $5 \%$ significance level using the identity and the efficient weighting matrices, and at the $10 \%$ level for the Hansen-Jagannathan weighting matrix, confirming the findings in Table 5 .

Thus, the model fails to explain the cross-section of returns. As pointed out, the above specification of the log of the stochastic discount factor as an affine function of the log consumption growth, the log price-dividend ratio of the market and the log risk free rate (or the difference in the log price-dividend ratios of the "Value" and "Growth" portfolios) could arise from other asset pricing models which have two latent state variables quite unrelated to long run risks in consumption growth and fluctuating volatility. Hence, failure of the above specification to explain the crosssection of returns suggests that no two-factor model, in conjunction with Kreps and Porteus (1978) preferences, succeeds in explaining the cross-section over the period 1930-2006.

To examine whether the rejection of the model in Tables 5 and 6 is due to its poor performance in the pre-war period, Tables 7 and 8 report estimation results for the subsample 1947-2003. Table 7 corresponds to the specification of the pricing kernel as in Table 5. Contrary to Table 5, the computed J-stat, using the identity weighting matrix, has a p-value exceeding 10\%. Also, the pricing errors for the assets are reduced by a factor of about 10 compared to Table 5. Panel B reveals that the specification is not rejected at the $10 \%$ level of significance for the Hansen-Jagannathan weighting matrix as well.

Table 8 reports results corresponding to the specification of the pricing kernel as in Table 6. Once again, we find that the specification is not rejected at the $10 \%$ level of significance for the identity weighting matrix and at the $5 \%$ level for the HasenJagannathan weighting matrix, contrary to Table 6 . Thus, while the model fails to explain the cross-section of returns over the full sample period, 1930-2006, it performs significantly better over the post-war period, 1947-2003.

As pointed out in Section 4, a full test of the LRR model should incorporate restrictions imposed by the assumed preferences of the representative agent and the time-series processes (1) on the parameters of the pricing kernel. The specification of the pricing kernel is rejected in Table 5 on the cross-section of returns over the period 1930-2006, even without the imposition of the restrictions. Not surprisingly, the rejection becomes stronger after the imposition of the restrictions. While the specification performs considerably better over the subsample 1947-2003 in Table 7, imposition of the restrictions leads to a strong rejection of the model. The computed J-stats at the calibrated values of the time-series and preference parameters for the identity and Hansen-Jagannathan weighting matrices are 17.14 and 28.97, respectively. Both have p-values smaller than $1 \%$.

As in Section 4, in order to assess the effects of the decision interval and time averaging, Tables 9 and 10 report estimation results for the cross-section, corresponding to the specification of the pricing kernel in Tables 7 and 8, respectively, using quarterly 
data over the period 1947:2-2003:3. Table 9 reveals that, without the imposition of the time-series restrictions, the specification is rejected using the identity matrix but not using the efficient and the Hansen-Jagannathan weighting matrices.The same results obtain for the alternative specification of the stochastic discount factor in Table 10. However, when the time-series restrictions are imposed on the parameters of the pricing kernel in Table 9, we find that the predicted coefficients of the first difference of the risk free rate and the first difference of the price-dividend ratio of the market, -43.62 and 1.467, respectively, are outside the one standard deviation intervals of the estimated values in Panels B and C. Moreover, the J-stats at the predicted parameter values, $65.01,38.83$, and 32.25 , respectively, for the identity, efficient and Hansen-Jagannathan weighting matrices, have p-values smaller than $1 \%$.

\section{Estimation of Time-Series Parameters and Sim- ulation Results}

In order to examine the finite-sample performance of the GMM estimators and the associated J-stats in Sections 4 and 5 and evaluate the plausibility of the LRR model, we estimate the parameters of the time-series processes (1). We assume that the model holds at the annual frequency and estimate the parameters such that the growth rates of consumption and dividends match salient features of observed annual data. The details of the estimation are given in Appendix A.2. In particular, the parameters are estimated using the GMM approach, where the chosen moments to match include the unconditional means, variances, and first-order autocovariances of consumption and dividend growth rates, the covariance between consumption and dividend growth rates, and the variances of the squared consumption and dividend growth rates. This gives an exactly identified set of 9 moment restrictions involving 9 parameters.

Table 11 reports estimated values of the time-series parameters, along with the standard errors in parentheses, for the full sample 1930-2006. Standard errors are Newey-West corrected using two lags. Note that the point estimate of the persistence parameter of the LRR variable, $\rho$, is 0.99 and is statistically significantly positive at conventional levels of significance. However, the persistence parameter of the stochastic volatility process, $v$, is quite imprecisely estimated and is not significantly different from zero.

Using the estimated values of the time-series parameters and setting the preference

parameters, $\delta, \gamma$, and $\psi$, to values 0.998, 10, and 1.5, respectively, as in Bansal and Yaron (2004), Table 12 reports simulation results to examine the finite-sample performance of the GMM estimators and test statistics in Table 2. The results reported are for 225 simulations with 76 observations each, corresponding to the choice of the 
historical sample. The Mean denotes the mean across simulations. Panel A displays results for the identity weighting matrix while Panel B reports the same for the efficient weighting matrix. The bottom row of each panel reports the 90th, 95th, and 99th percentiles of the simulated distributions of the J-stats. For the identity weighting matrix, the bottom line of Panel A reveals that the model is not rejected even at the $10 \%$ level of significance using the percentiles of the simulated distribution - the J-stat at the bottom line of Table 2, Panel A at 0.001 is much smaller than the 90th percentile of the simulated distribution of the J-stat, the latter being 0.018. This inference reinforces the corresponding asymptotic inference using the asymptotic distribution of the J-stat. For the efficient weighting matrix, the model is rejected at the $5 \%$ level but not at the $1 \%$ level, using the percentiles of the simulated distribution of the J-stat, as revealed by the bottom line of Table 12, Panel B. Overall, the finite-sample results in Table 12 largely conform with the asymptotic inference in Table 2.

Table 13 reports simulation results to examine the finite-sample performance of the GMM estimators and test statistics in Table 5. Once again, the finite-sample inference is largely consistent with the asymptotic inference. In particular, for the identity and the Hansen-Jagannathan weighting matrices, the model is rejected at the $5 \%$ and $10 \%$ levels, respectively, while for the efficient weighting matrix, the J-stat has a p-value marginally higher than $10 \%$.

Table 14 reports estimated values of the time-series parameters, along with the standard errors in parentheses, for the post-war period 1947-2003. In this case, the persistence parameters of both, the LRR variable and the stochastic volatility process are statistically indistinguishable from zero. Also, the mean of the volatility process, $\sigma^{2}$, is lower in the subsample reflecting the high economic uncertainty during the period of the great depression and World War II. The finite-sample results, based on simulations using these point estimates, largely conform with the asymptotic inference in Tables 3 and 7 , and, hence, are omitted for brevity.

\section{Empirical Evidence on the Joint Pricing and Time- Series Implications of the LRR Model}

As pointed out in Sections 4 and 5, a full test of the LRR model should incorporate restrictions on the parameters of the pricing kernel, imposed by the assumed preferences of the representative agent and the time-series processes. In Sections 4 and 5, we examined the plausibility of the model by using the estimated values of the time-series parameters and plausibly calibrated values of the preference parameters to obtain the "predicted" values of the parameters of the pricing kernel. The time-series parameters were estimated using the GMM approach to match a comprehensive set of moments 
of consumption and dividend growth rates. The predicted values of the parameters of the pricing kernel were then compared to the estimated values of the same, the latter being obtained by estimating the Euler equations for a set of assets without imposing any restrictions on the parameters.

It should be noted that the time-series parameters are estimated with error. Table 11 reports the point estimates of the time series parameters along with the associated standard errors. A complete assessment of the model requires taking into account the estimation error of the time-series parameters. To this end, we perform a ninedimensional grid search over the nine time series parameters. For the persistence parameters of the LRR variable, $\rho$, and the stochastic volatility process, $v$, the grid covers the interval 0.1-0.9, with increments of 0.1. From Table 8, we see that this interval is the $95 \%$ confidence interval of these parameters within their permissible range $(0,1]$. For the other seven parameters, the grid consists of five evenly spaced points within two standard errors of the point estimates. Thus, the grid consists of points. At each of the $\left(9^{2} \times 5^{7}\right)$ grid points, we compute the parameters of the pricing kernel, predicted by the assumed preferences and time-series specification of the model, and the associated J-stat.

In the full sample, 1930-2006, the minimum J-stat for the identity weighting matrix obtained over the grid is 0.218 , which has a p-value smaller than $1 \%$ (see critical values at the end of Table 2). The corresponding predicted values of the parameters of the pricing kernel are $-0.574,-10.00,-27.24$, and -3.879 , respectively. Note that the predicted value of the coefficient of the first difference of the risk free rate, -27.24 , is outside the $95 \%$ confidence interval of the estimated values, -1.973 and -13.78 , respectively, in Panels A and B of Table 2. Thus, the model is strongly rejected even with the extensive grid search.

In the post-war period, the results are mixed. Table 14 reports the point estimates of the time series parameters along with the associated standard errors for the postwar annual sample, 1947-2003. Performing a grid search over the nine time series parameters, we find that the minimum J-stat over the grid points is 0.019 which is not rejected at the $1 \%$ level of significance (see critical values at the end of Table 3 ). The corresponding predicted values of the parameters of the pricing kernel, - 0.274 , $-10.00,-30.45,-2.010$, respectively, are all within the one standard error intervals of the estimated values in Table 3. However, the value of the persistence parameter of the LRR variable, $\rho$, that best fits the data is 0.5 , implying that the half-life of the LRR variable is one year and its implied frequency is much higher than that of the business cycle and of most state variables put forth in the asset pricing literature.

These results raise the possibility that the shift in the mean growth rate of consumption and dividends may be of higher frequency than what has been emphasized in the literature. If we force a low-frequency LLR variable in the post-war period, the model does not fit the data. When we set $\rho=0.9$ (or, 0.8) in the grid search, with the implication that the half-life of the LLR variable is 6.6 (or, 3.1) years, the minimum J- 
stat is 0.067 (or, 0.121) and the model is rejected at the $1 \%$ level of significance. When we set $\rho=0.979$ (the calibrated value in Bansal and Yaron (2004)), the minimum J-stat is 1.394 and again the model is rejected at the $1 \%$ level of significance. ${ }^{3}$

We check the robustness of the model when the model period is taken to be one quarter rather than one year. Problems with temporal aggregation are likely to be less severe at the quarterly frequency. We perform a grid search over the nine time series parameters. Table 15 reports the point estimates of the time series parameters along with the associated standard errors over the period 1947:2-2003:3. The minimum J-stat is 0.346 at $\rho=0.8$, implying that the half-life of the LLR variable is 3.1 quarters. Although the J-stat is rejected at the $1 \%$ level of significance (see critical values at the end of Table 4), the corresponding predicted values of the parameters of the pricing kernel, $-0.196,-10.0,-32.77$, and -3.858 , respectively, are all within the $95 \%$ confidence intervals of the estimated values in Table 4. Setting $\rho=0.979$, as in Bansal and Yaron (2004), leads to a minimum J-stat of 23.67, considerably reinforcing the rejection of the model. Moreover, in this case, the predicted value of the coefficient of the first difference of the risk free rate, -144.9 , is outside the $95 \%$ confidence interval of the estimated value in Table 4.

A similar set of results obtain for the cross-section of asset returns. The specification of the pricing kernel is rejected in Tables 5 and 6 on the cross-section of returns over the period 1930-2006, even without imposing time-series restrictions. Not surprisingly, the rejection becomes stronger after imposing the restrictions. The specification performs considerably better over the post-war subsample 1947-2003 in Tables 7 and 8 and the pricing equations are not rejected when the restrictions are not imposed. In Table 7, the grid search over the time-series parameters gives a minimum J-stat of 0.108 for the identity weighting matrix. Although this is marginally higher than the $1 \%$ critical value (see critical values at the end of Table 7 ), the predicted values of the parameters of the pricing kernel, $-0.336,-10.00,-31.29$, and -2.500 , respectively, are all within one standard error of the corresponding estimated values. The minimum J-stat is obtained for $\rho=0.5$, and rises to 0.372 when it is set at 0.979 . Finally, the results are very similar for quarterly data, with the minimum J-stat, 0.110 , being obtained at $\rho=0.4$. The predicted value of the pricing kernel parameters are within one standard error of the estimated values in Table 9 . Setting $\rho=0.979$ raises the minimum J-stat to 1.220 . In this case, the predicted values of the coefficients of the first difference of the risk free rate and the first difference of the market price-dividend ratio, -144.9 and -5.237 , respectively, are outside one standard error of the estimated values in Table 9.

\footnotetext{
${ }^{3}$ The LRR variable is latent and very difficult to estimate (see Shephard and Harvey (1990)). By expressing the latent state variables as an affine function of observables, our methodology provides a data-driven way of examining the plausibility of the risk channels highlighted in the LRR literature as well as the frequencies of the risk factors.
} 


\section{An Extended Long Run Risks Model}

We consider a variant of the Bansal, Gallant, and Tauchen (2007) model that is an extension of Bansal and Yaron (2004). In particular, the aggregate dividend growth, the LRR variable, and the stochastic volatility processes are as in Bansal and Yaron (2004),

$$
\begin{aligned}
\Delta c_{t+1} & =\mu+x_{t}+\sigma_{t} z_{d, t+1} \\
x_{t+1} & =\rho_{x} x_{t}+\varphi_{e} \sigma_{t} z_{x, t+1} \\
\sigma_{t+1}^{2} & =(1-v) \sigma^{2}+v \sigma_{t}^{2}+\sigma_{w} z_{\sigma, t+1}
\end{aligned}
$$

The point of departure from the Bansal and Yaron (2004) model is the imposition of a cointegrating restriction between log aggregate stock market dividends, $d_{t}^{m}$, and log consumption, $c_{t}$,

$$
d_{t}-c_{t}=\mu_{d c}+s_{t}
$$

where $s_{t}$ is an $I(0)$ process,

$$
s_{t+1}=\lambda_{s x} x_{t}+\rho_{s} s_{t}+\psi_{s} \sigma_{t} z_{s, t+1}
$$

The shocks $z_{d, t+1}, z_{x, t+1}, z_{\sigma, t+1}, z_{s, t+1}$ are assumed to be i.i.d. $N(0,1)$ and mutually independent. Note that the cointegrating coefficient is set at one in equation (14). Bansal, Gallant, and Tauchen (2005) argue that this restriction is economically well motivated because aggregate consumption and dividends cannot permanently deviate from each other and financial wealth cannot permanently deviate from aggregate wealth. They also perform a heteroskedasticity-robust augmented Dickey-Fuller test for a unit root in $d_{t}^{m}-c_{t}$ and the results provide strong evidence for a cointegrating relationship between the variables with a coefficient equal to unity. Bansal, Dittmar, and Kiku (2007) highlight that this cointegrating relation measures long run covariance risks in dividends and is important in understanding sources of risk and explaining the equity risk premia across all investment horizons. ${ }^{4}$

From equation (14), we have,

$$
\begin{aligned}
\Delta d_{t+1} & =\Delta c_{t+1}+\Delta s_{t+1} \\
& =\mu_{c}+\left(1+\lambda_{s x}\right) x_{t}+\left(\rho_{s}-1\right) s_{t}+\sigma_{t} z_{c, t+1}+\psi_{s} \sigma_{t} z_{s, t+1}
\end{aligned}
$$

\footnotetext{
${ }^{4}$ In a different context, Lettau and Ludvigson (2001) and Menzly, Santos, and Veronesi (2004) apply the cointegrating residual between consumption, labour income, and dividends to explain the cross-section of asset returns.
} 
where the second line follows from equations (13) and (15).

Thus, this extension of the LRR model involves three state variables- the LRR variable, $x_{t}$, the stochastic volatility, $\sigma_{t}^{2}$, and the cointegrating residual between log aggregate dividends and log aggregate consumption, $s_{t}$. Note that the Bansal and Yaron (2004) model with two latent state variables obtains as a special case when $\rho_{s}=1$.

The estimation methodology outlined in Section 2 can readily be adapted to the extended version of the model. Note that two of the three state variables, namely, the long run risk variable, $x_{t}$, and the stochastic volatility, $\sigma_{t}^{2}$, are latent, while the cointegrating residual, $s_{t}$, is observable (see equation (14)). Appendix A.3 establishes that, for this extended specification, the log price-dividend ratio of the market is an affine function of the three state variables, $x_{t}, \sigma_{t}^{2}$, and $s_{t}$. The log risk free rate and the log price-consumption ratio, on the other hand, are functions only of $x_{t}$ and $\sigma_{t}^{2}$,

$$
\begin{aligned}
z_{m, t} & =A_{0, m}+A_{1, m} x_{t}+A_{2, m} \sigma_{t}^{2}+A_{3, m} s_{t} \\
z_{t} & =A_{0}+A_{1} x_{t}+A_{2} \sigma_{t}^{2} \\
r_{f, t} & =A_{0, f}+A_{1, f} x_{t}+A_{2, f} \sigma_{t}^{2}
\end{aligned}
$$

Equations (17) and (19) may be inverted to express the unobservable state variables, $x_{t}$ and $\sigma_{t}^{2}$, in terms of the observables, $z_{m, t}, r_{f, t}$, and $s_{t}$, (see Appendix A.3 for details),

$$
\begin{aligned}
x_{t} & =\alpha_{0}+\alpha_{1} r_{f, t}+\alpha_{2} z_{m, t}+\alpha_{3} s_{t} \\
\sigma_{t}^{2} & =\beta_{0}+\beta_{1} r_{f, t}+\beta_{2} z_{m, t}+\beta_{3} s_{t}
\end{aligned}
$$

Now, from equations (3), (4), and (18),

$$
\begin{aligned}
m_{t+1}= & \left(\theta \log \delta+(\theta-1)\left[\kappa_{0}+\left(\kappa_{1}-1\right) A_{0}\right]\right)+\left(-\frac{\theta}{\psi}+(\theta-1)\right) \Delta c_{t+1} \\
& +(\theta-1) \kappa_{1} A_{1} x_{t+1}+(\theta-1) \kappa_{1} A_{2} \sigma_{t+1}^{2} \\
& -(\theta-1) A_{1} x_{t}-(\theta-1) A_{2} \sigma_{t}^{2}
\end{aligned}
$$

Substituting the expressions for $x_{t}$ and $\sigma_{t}^{2}$ from equations (20) and (21) into the pricing kernel, equation (22), we have

$$
\begin{aligned}
m_{t+1} & =c_{1}+c_{2} \Delta c_{t+1}+c_{3} z_{m, t+1}+c_{4} r_{f, t+1}+c_{5} s_{t+1}+c_{6} z_{m, t}+c_{7} r_{f, t}+c_{8} s_{t} \\
& \approx c_{1}+c_{2} \Delta c_{t+1}+c_{3}\left(r_{f, t+1}-r_{f, t}\right)+c_{4}\left(z_{m, t+1}-z_{m, t}\right)+c_{5}\left(s_{t+1}-s_{t}\right)
\end{aligned}
$$

The second line follows since $c_{3} \approx-c_{6}, c_{4} \approx-c_{7}$ and $c_{5} \approx-c_{8}$ (see Appendix A.1.3 and A.3 for details). The above expression for the pricing kernel is entirely in terms of 
observables and the parameters $c=\left(c_{1}, c_{2}, c_{3}, c_{4}, c_{5}\right)^{\prime}$ may be estimated from the Euler equations for a set of logarithmic portfolio returns $\left\{r_{1, t+1}, \ldots, r_{n, t+1}\right\}_{t=1}^{T}$, as in Section 2.

\section{Empirical Evidence on the Extended Model}

We present the estimation and test results for the extended version of the LRR model, outlined in the preceeding section. Table 16 reports estimation results of the Euler equations (2), over the annual sample period 1930-2006, when the set of assets consists of the market portfolio and the risk free rate, and the lagged log price-dividend ratio of the market and the lagged log risk free rate are used as instruments. The observable variables employed to express the latent state variables, the LLR and the stochastic volatility, as affine functions of the former include the log price-dividend ratio of the market and the log risk free rate, as detailed in Section 8. Panels A and B report results for the identity and the efficient weighting matrices, respectively. Note that the estimated coefficient of the first difference of the log price-dividend ratio of the market is statistically significant in Panels A and B, while all other estimated coefficients are not significantly different from zero in both panels. The J-stat in Panel A shows that the model is rejected at the $5 \%$ level of significance but not at the $1 \%$ level, when the identity weighting matrix is used. Moreover, Table 16, Panel B reveals that, using the efficient weighting matrix, the computed J-stat has a p-value of $59 \%$ using the asymptotic critical values.

As pointed out in Section 4, a full test of the extended LRR model should incorporate restrictions imposed by the assumed preferences of the representative agent and the time-series processes (equations (13), (14), (15), and (16)) on the parameters of the pricing kernel. In order to ascertain the plausibility of the risk channels in the model, we note that the model implies that the parameters of the stochastic discount factor are functions of the underlying time-series and preference parameters (see Appendix A.3 for details). We estimate the time-series parameters to match a comprehensive set of moments of consumption and dividend data (see Appendix A.4 for details regarding the choice of moments and corresponding expressions for the chosen moments). Table 17 reports the point estimates of the time-series parameters along with the associated standard errors. These estimated values, along with plausibly calibrated values of the preference parameters (these are set to the values in Bansal and Yaron (2004)), are used to compute the "predicted" values of the parameters of the pricing kernel. The latter are then compared to the estimated values in order to examine the plausibility of the model. Note that the coefficient on the first difference of the log risk free rate predicted by the model is -30.48 , which is outside the $95 \%$ confidence interval of the estimated value for the identity weighting matrix (Table 16, Panel A) and beyond one standard 
error of the estimated value for the efficient weighting matrix (Table 16, Panel B). The J-stats computed at these predicted values are 4193.8 and 10.34 for the identity and efficient weighting matrices, respectively. Both have p-values smaller than $1 \%$.

However, as noted in Section 7, the time-series parameters are measured with error. Hence, we evaluate the model over a set of grid points. As in Section 7, for the persistence parameters of the LRR variable, the stochastic volatility process, and that of the cointegrating residual, the grid covers the interval 0.1-0.9, with increments of 0.1. For the other parameters, the grid includes five evenly spaced points that cover a two standard errors interval around the point estimate. The minimum J-stat across these grid points is 20.30 for the identity weighting matrix which is several orders of magnitude bigger than the $1 \%$ critical value (see critical values at the end of Table 16). The corresponding predicted values of the parameters of the pricing kernel are 0.138 , $-10.0,-5.330,-1.983$, and -1.487 , respectively. Note that the predicted value of the coefficient on the first difference of the log price-dividend ratio of the market, -1.983 , is beyond one standard error of the estimated values in Panels A and B.

Table 18 reports estimation results for the same set of assets and choice of instruments over the post-war period 1947-2003. Here, we only report results for the identity weighting matrix because of the poor finite-sample properties of efficient GMM for a small sample size. Table 19 shows the time-series parameter estimates for this subsample. A grid search over these time-series and preference parameters gives a minimum J-stat of 14.38. Although this has a p-value smaller than $1 \%$ (see critical values at the end of Table 18), the predicted values of the parameters of the pricing kernel, 0.119, $-10.0,-12.30,-1.450$, and -1.088 , respecively, are all within one standard error of the corresponding estimated values. This result is attained at $\rho_{x}=0.1$. Forcing the persistence parameter of the LRR variable to have a frequency lower than the business cycle, 0.9, raises the minimum J-stat of 523.9 .

Similar results are obtained with post-war quarterly data. A grid search over the time-series and preference parameters (Table 21 reports the estimates of the timeseries parameters and the associated standard errors for post-war quarterly data) gives a minimum J-stat of 7.391 . Although this has a p-value smaller than $1 \%$ (see critical values at the end of Table 20), the predicted values of the parameters of the pricing kernel, $0.035,-10.0,-17.24,-0.065$, and -0.049 , respecively, are all within one standard error of the corresponding estimated values. This result is attained at $\rho_{x}=0.2$. Forcing the persistence parameter to equal 0.9, raises the minimum J-stat of 2448.7. In this case, the coefficient on the first difference of the log risk free rate predicted by the model is -85.66 , which is outside the one standard error interval of the estimated value for either choice of the weighting matrix.

Table 22 reports estimation results for the full sample 1930-2006 when the set of assets includes the market, the risk free rate, the "Small", "Large", "Growth", and "Value" portfolios. Table 22, Panel A, shows that the model is rejected at the $1 \%$ level of significance using the identity weighting matrix. However, Table 22, Panel B, 
reveals that using the efficient weighting matrix, the computed J-stat has p-value of $51 \%$, using the asymptotic critical values. Also, Table 22, Panel C, reveals that using the Hansen-Jagannathan weighting matrix, the computed J-stat has p-value exceeding $10 \%$.

Overall, Table 22 reveals that the three-factor extended version of the LRR model performs much better at explaining the cross-section of returns compared to the original Bansal and Yaron (2004) two-factor specification (Tables 5 and 6). However, imposition of the time-series restrictions gives a minimum J-stat of 11.46. The predicted values of the parameters of the pricing kernel, $0.138,-10.0,-5.330,-1.983$, and -1.487 , respecively. Note that the predicted coefficient of the first difference of the log dividend-consumption ratio, -1.487 , is outside the $95 \%$ confidence interval of the estimated values in Panels $\mathrm{A}$ and $\mathrm{B}$ and outside the one standard error interval in Panel C of Table 22.

Table 23 reports results for the cross-section for the post-war annual period 19472003. Imposition of the time-series restrictions gives a minimum J-stat of 5.409 and the predicted values of the parameters of the pricing kernel are all within one standard error intervals of the corresponding estimated values. This is obtained at $\rho_{x}=0.1$. Forcing the persistence parameter to equal 0.9, raises the minimum J-stat of 104.7. In this case, the coefficient on the first difference of the log price-dividend ratio of the market predicted by the model is -7.407 , which is outside the $95 \%$ confidence interval of the estimated values for either choice of the weighting matrix.

Finally, Table 24 reports results for the cross-section for the post-war quarterly sample 1947:2-2003:3. The results are largely similar to Table 23. Imposition of the time-series restrictions gives a minimum J-stat of 1.699 and the predicted values of the parameters of the pricing kernel are all within one standard error intervals of the corresponding estimated values. This is obtained at $\rho_{x}=0.2$. Forcing the persistence parameter to equal 0.9 , raises the minimum J-stat of 328.6 .

\section{Conclusion}

In this paper we test and reject the Bansal and Yaron (2004) model of long-run risks in aggregate consumption and dividend growth and its extension that captures potential cointegration of the consumption and dividend levels. The reversal of earlier empirical conclusions is partly due to the increase in the power of the tests resulting from two observations under the null hypothesis. First, the latent state variables, and, therefore, the pricing kernel are known affine functions of observables such as the interest rate and the market-wide price-dividend ratio. Second, the parameters of the time-series processes of consumption and dividend growth, the LRR variable, and its conditional variance impose constraints on the parameters of the pricing kernel.

This increase in power heavily relies upon taking literally the log-linearized model under the null. It is plausible that the basic intuition of the long run risks model is valid 
yet the model is rejected for other reasons, such as misspecification of the particular time-series processes of consumption and dividend growth, the LRR variable, and its conditional variance. One example of generalizing the time-series processes is to allow for a regime shift in these processes. We also demonstrate that while the two-factor model at the annual frequency, even without imposition of the time-series restrictions, fails to price the cross-section over the period 1930-2006, the model is not rejected over the subperiod 1947-2003, consistent with a regime shift in the post-war period. In this paper, we address this issue only to the extent that we present estimation results for both, the full period, 1930-2006, and the 1947-2003 subperiod. A more detailed study should build into the time-series processes the possibility of a regime shift. We are currently addressing this class of issues. 


\section{References}

[1] Alvarez, F., and Jermann, U., (2005), "Using Asset Prices to Measure the Persistence of the Marginal Utility of Wealth," Econometrica, 73(6), 1977-2016.

[2] Bansal, R., Dittmar, R.F., and Kiku, D., (2007), "Cointegration and Consumption Risks in Asset Returns," Forthcoming in Review of Financial Studies.

[3] Bansal, R., Dittmar, R.F., and Lundblad, C., (2005), "Consumption, Dividends, and the Cross-Section of Equity Returns," Journal of Finance 60, 1639-1672.

[4] Bansal, R., Gallant, R., and Tauchen, G., (2005), "Rational Pessimism, Rational Exhuberance, and Markets for Macro Risk," Forthcoming in Review of Financial Studies.

[5] Bansal, R., Kiku, D., and Yaron, A., (2007), "Risks For the Long Run: Estimation and Inference," Working Paper.

[6] Bansal, R., and Yaron, A., (2004), "Risks for the Long Run: A Potential Resolution of Asset Pricing Puzzles," Journal of Finance, 1481-1509.

[7] Bekaert, G., Engstrom, E., and Xing, Y., (2005), "Risk, Uncertainty, and Asset Prices," Working Paper.

[8] Brav, A., Constantinides, G.M., and Geczy, C., (2002), "Asset Pricing with Heterogeneous Consumers and Limited Participation: Empirical Evidence," Journal of Political Economy, 110, 793-824.

[9] Bui, M. P., (2007), "Long-Run Risks and Long-Run Predictability: A Comment," Working paper, Harvard University.

[10] Campbell, J.Y., (2000), "Asset Pricing at the Millennium," Journal of Finance, $55(4), 1515-1567$.

[11] Campbell, J.Y., (2003), "Consumption-Based Asset Pricing," in Handbook of the Economics of Finance, Vol. I-B, ed. by G. M. Constantinides, M. Harris, and R. Stulz, pp. 803-887. North Holland, Amsterdam.

[12] Campbell,J., and Cochrane, J., (1999), "By Force of Habit: A Consumption-Based Explanation of Aggregate Stock Market Behavior," Journal of Political Economy, 107, 205-251.

[13] Campbell, J.Y., Lo, A.W., and MacKinlay, C., (1997), "The Econometrics of Financial Markets," Princeton University Press, Princeton, NJ. 
[14] Campbell, J.Y., and Shiller, R.J., (1988), "The Dividend-Price Ratio and Expectations of Future Dividends and Discount Factors," Review of Financial Studies, $1,195-227$.

[15] Cochrane, J.H., (2005), "Asset Pricing," Revised Edition. Princeton University Press, Princeton, NJ.

[16] Cochrane, J.H., and Hansen, L.P., (1992), "Asset Pricing Explorations for Macroeconomics," Macroeconomics Annual.

[17] Constantinides, G.M., (2002), "Rational Asset Prices," Journal of Finance, 57(4), 1567-1591.

[18] Constantinides, G.M., (1990), "Habit Formation: A Resolution of the Equity Premium Puzzle," Journal of Political Economy, 98(2), 519-543.

[19] Constantinides, G.M., and Duffie, D., (1996), "Asset Pricing with Heterogeneous Consumers," Journal of Political Economy, 104(2), 219-240.

[20] Constantinides, G.M., and Ferson, W.E., (1991), "Habit Persistence and Durability in Aggregate Consumption: Empirical Tests," Journal of Financial Economics, 29, 199-240.

[21] Dai, Q., and Singleton, K.J., (2000), "Specification Analysis of Affine Term Structure Models," Journal of Finance, 55, 1943-1978.

[22] Epstein, L.R., and Zin, S.E., (1989), "Substitution, Risk Aversion, and the Temporal Behavior of Consumption and Asset Returns: A Theoretical Framework," Econometrica, 57, 937-969.

[23] Fama, E.F., and French, K.R., (1993), "Common Risk Factors in the Returns on Stocks and Bonds." J. Financial Econ. 33, 3-56.

[24] Hansen, L.P., (1982), "Large Sample Properties of Generalized Method of Moments Estimators," Econometrica, 50, 1029-1054.

[25] Hansen, L.P., Heaton, J., and Li, N., (2005), "Consumption Strikes Back," Working Paper, University of Chicago.

[26] Hansen, L.P., and Jagannathan, R., (1997), "Assessing Specification Errors in Stochastic Discount Factor Models," Journal of Finance, 52, 557-590.

[27] Hansen, L.P., and Scheinkman, J., (2007), "Long-Term Risk : An Operator Approach," Working Paper. 
[28] Jagannathan, R., and Wang, Z., (1996), "The Conditional CAPM and the Cross Section of Expected Returns," Journal of Finance, 51, 3-53.

[29] Kiku, D., (2006), "Long Run Risks and the Value Premium Puzzle," Working Paper, Duke University.

[30] Kocherlakota, N., (1996), "The Equity Premium: It's Still A Puzzle," Journal of Economic Literature, 34(1), 42-71.

[31] Kreps, D.M., and Porteus, E.L., (1978), "Temporal Resolution of Uncertainty and Dynamic Choice Theory," Econometrica, 46(1), 185-200.

[32] Lettau, M., and Ludvigson, S., (2001), "Resurrecting the C(CAPM): A CrossSectional Test When Risk Premia are Time-Varying." Journal of Political Economy, 109: 1238-87.

[33] Lettau, M., and Ludvigson, S., (2007), "Euler Equation Errors," Working Paper, New York University.

[34] Mehra, R., (2008), "Handbook of the Equity Risk Premium," ed., Elsevier, Amsterdam.

[35] Mehra, R., and Prescott, E. C., (2003), "The Equity Premium Puzzle in Retrospect," in Handbook of the Economics of Finance, Vol. I-B, ed. by G. M. Constantinides, M. Harris, and R. Stulz, pp. 803-887. North Holland, Amsterdam.

[36] Malloy, C., Moskowitz, T., and Vissing-Jorgensen, A., (2006), "Long-Run Stockholder Consumption Risk and Asset Returns," Working Paper, University of Chicago.

[37] Menzly, L., Santos, T., and Veronesi, P., (2004), "Understanding Predictability," Journal of Political Economy, 112(1), 1-47.

[38] Parker, J.A., and Julliard, C., (2005), "Consumption Risk and the Cross Section of Expected Returns," Journal of Political Economy, 113(1), 185-222.

[39] Tauchen, G., (2005), "Stochastic Volatility in General Equilibrium," Working Paper.

[40] Vissing-Jorgensen, A., (2002), "Limited Asset Market Participation and the Elasticity of Intertemporal Substitution," Journal of Political Economy, 110(4), 825853.

[41] Weil, P., (1989), "The Equity Premium Puzzle and the Risk-Free Rate Puzzle," Journal of Monetary Economics, 24(3), 401-421. 


\section{A Appendix}

\section{A.1 Details of Estimation Methodology}

The model is given by the equations

$$
\begin{aligned}
x_{t+1} & =\rho_{x} x_{t}+\psi_{x} \sigma_{t} e_{t+1} \\
\sigma_{t+1}^{2} & =\sigma^{2}+v_{1}\left(\sigma_{t}^{2}-\sigma^{2}\right)+\sigma_{w} w_{t+1} \\
\Delta c_{t+1} & =\mu+x_{t}+\sigma_{t} \eta_{t+1} \\
\Delta d_{t+1}^{m} & =\mu_{d}^{m}+\phi_{d}^{m} x_{t}+\varphi_{d}^{m} \sigma_{t} u_{t+1}
\end{aligned}
$$

The shocks $\eta_{t+1}, e_{t+1}, w_{t+1}, u_{t+1}$ are assumed to be i.i.d.N(0,1) and mutually independent.

\section{A.1.1 Risk Free Rate}

To derive the expression for the risk free rate, note that

$$
E_{t}\left[\exp \left(\theta \log \delta-\frac{\theta}{\psi} \Delta c_{t+1}+(\theta-1) r_{c, t+1}+r_{f, t}\right)\right]=1
$$

Hence,

$$
\begin{aligned}
\exp \left(-r_{f, t}\right)= & E_{t}\left[\exp \left(\theta \log \delta-\frac{\theta}{\psi} \Delta c_{t+1}+(\theta-1) r_{c, t+1}\right)\right] \\
= & \exp \left(\theta \log \delta-\frac{\theta}{\psi} \mu-\frac{\theta}{\psi} x_{t}+(\theta-1) \kappa_{0}+(\theta-1) \kappa_{1} A_{0}\right. \\
& +(\theta-1) \kappa_{1} A_{1} \rho_{x} x_{t}+(\theta-1) \kappa_{1} A_{2}\left(1-v_{1}\right) \sigma^{2}+(\theta-1) \kappa_{1} A_{2} v_{1} \sigma_{t}^{2} \\
& -(\theta-1) A_{0}-(\theta-1) A_{1} x_{t}-(\theta-1) A_{2} \sigma_{t}^{2}+(\theta-1) \mu+(\theta-1) x_{t} \\
& +0.5\left[\left(-\frac{\theta}{\psi}+\theta-1\right)^{2} \sigma_{t}^{2}+(\theta-1)^{2} \kappa_{1}^{2} A_{1}^{2} \varphi_{e}^{2} \sigma_{t}^{2}+(\theta-1)^{2} \kappa_{1}^{2} A_{2}^{2} \sigma_{w}^{2}\right]
\end{aligned}
$$

Therefore, the risk free rate is 


$$
\begin{aligned}
r_{f, t}= & -\theta \log \delta-\left(-\frac{\theta}{\psi}+\theta-1\right) \mu-(\theta-1) \kappa_{0}-(\theta-1)\left(\kappa_{1}-1\right) A_{0}-(\theta-1) \kappa_{1} A_{2}\left(1-v_{1}\right) \sigma^{2} \\
& -0.5(\theta-1)^{2} \kappa_{1}^{2} A_{2}^{2} \sigma_{w}^{2}-\left[\left(-\frac{\theta}{\psi}+\theta-1\right)+(\theta-1)\left(\kappa_{1} \rho_{x}-1\right) A_{1}\right] x_{t} \\
& -\left[(\theta-1)\left(\kappa_{1} v_{1}-1\right) A_{2}+0.5\left(\left(-\frac{\theta}{\psi}+\theta-1\right)^{2}+(\theta-1)^{2} \kappa_{1}^{2} A_{1}^{2} \varphi_{e}^{2}\right)\right] \sigma_{t}^{2} \\
= & A_{0, f}+A_{1, f} x_{t}+A_{2, f} \sigma_{t}^{2}
\end{aligned}
$$

\section{A.1.2 Latent state variables in terms of observable variables}

The model implies

$$
\begin{aligned}
z_{m, t} & =A_{0, m}+A_{1, m} x_{t}+A_{2, m} \sigma_{t}^{2} \\
r_{f, t} & =A_{0, f}+A_{1, f} x_{t}+A_{2, f} \sigma_{t}^{2}
\end{aligned}
$$

These equations may be inverted to express the state variables in terms of the observables,

$$
x_{t}=\alpha_{0}+\alpha_{1} r_{f, t+1}+\alpha_{2} z_{m, t}
$$

where

$$
\begin{aligned}
\alpha_{0} & =\frac{A_{2, m} A_{0, f}-A_{0, m} A_{2, f}}{A_{1, m} A_{2, f}-A_{2, m} A_{1, f}} \\
\alpha_{1} & =\frac{-A_{2, m}}{A_{1, m} A_{2, f}-A_{2, m} A_{1, f}} \\
\alpha_{2} & =\frac{A_{2, f}}{A_{1, m} A_{2, f}-A_{2, m} A_{1, f}}
\end{aligned}
$$

and

$$
\sigma_{t}^{2}=\beta_{0}+\beta_{1} r_{f, t+1}+\beta_{2} z_{m, t}
$$

where 


$$
\begin{aligned}
\beta_{0} & =\frac{A_{0, m} A_{1, f}-A_{1, m} A_{0, f}}{A_{1, m} A_{2, f}-A_{2, m} A_{1, f}} \\
\beta_{1} & =\frac{A_{1, m}}{A_{1, m} A_{2, f}-A_{2, m} A_{1, f}} \\
\beta_{2} & =\frac{-A_{1, f}}{A_{1, m} A_{2, f}-A_{2, m} A_{1, f}}
\end{aligned}
$$

\section{A.1.3 The pricing kernel in terms of observables}

The pricing kernel is given by (equation (3)),

$$
\begin{aligned}
m_{t+1}= & \left(\theta \log \delta+(\theta-1)\left[\kappa_{0}+\left(\kappa_{1}-1\right) A_{0}\right]\right)+\left(-\frac{\theta}{\psi}+(\theta-1)\right) \Delta c_{t+1} \\
& +(\theta-1) \kappa_{1} A_{1} x_{t+1}+(\theta-1) \kappa_{1} A_{2} \sigma_{t+1}^{2}-(\theta-1) A_{1} x_{t}-(\theta-1) A_{2} \sigma_{t}^{2}
\end{aligned}
$$

Substituting the expressions for $x_{t}$ and $\sigma_{t}^{2}$ from Section A.2 into the pricing kernel, we have

$$
m_{t+1}=c_{1}+c_{2} \Delta c_{t+1}+c_{3} r_{f, t+1}+c_{4} r_{f, t}+c_{5} z_{m, t+1}+c_{6} z_{m, t}
$$

where

$$
\begin{aligned}
& c_{1}=\theta \log \delta+(\theta-1)\left[\kappa_{0}+\left(\kappa_{1}-1\right)\left(A_{0}+A_{1} \alpha_{0}+A_{2} \beta_{0}\right)\right] \\
& c_{2}=-\frac{\theta}{\psi}+(\theta-1) \\
& c_{3}=(\theta-1) \kappa_{1}\left[A_{1} \alpha_{1}+A_{2} \beta_{1}\right] \\
& c_{4}=-(\theta-1)\left[A_{1} \alpha_{1}+A_{2} \beta_{1}\right] \\
& c_{5}=(\theta-1) \kappa_{1}\left[A_{1} \alpha_{2}+A_{2} \beta_{2}\right] \\
& c_{6}=-(\theta-1)\left[A_{1} \alpha_{2}+A_{2} \beta_{2}\right]
\end{aligned}
$$

Since $\kappa_{1} \equiv \frac{e^{\bar{z}}}{1+e^{\bar{z}}} \approx 0.997$, we have $c_{3} \approx-c_{4}$ and $c_{5} \approx-c_{6}$.

\section{A.2 Estimation of Time-Series Parameters}

The decision interval of the agent is assumed to be annual. We estimate the model at the annual frequency, such that its annual growth rates of consumption and dividends 
match salient features of observed annual consumption and dividend data. There are 9 parameters to be calibrated $-\mu, \mu_{d}, \phi, \varphi_{d}, \rho, \varphi_{e}, \sigma^{2}, v, \sigma_{w}$.

From the specification of the consumption growth process, we have

$$
E\left(\Delta c_{t+1}\right)=\mu
$$

We also, have

$$
\begin{aligned}
\operatorname{Var}\left(\Delta c_{t+1}\right) & =\operatorname{Var}\left(x_{t}\right)+\operatorname{Var}\left(\sigma_{t} \eta_{t+1}\right)+2 \operatorname{Cov}\left(x_{t}, \sigma_{t} \eta_{t+1}\right) \\
& =\operatorname{Var}\left(x_{t}\right)+\sigma^{2}+0 \\
& =\frac{\varphi_{e}^{2} \sigma^{2}}{1-\rho^{2}}+\sigma^{2}
\end{aligned}
$$

and,

$$
\operatorname{Cov}\left(\Delta c_{t+1}, \Delta c_{t+2}\right)=\rho \frac{\varphi_{e}^{2} \sigma^{2}}{1-\rho^{2}}
$$

From the specification of the quarterly dividend process, we have

$$
\begin{gathered}
E\left(\Delta d_{t+1}\right)=\mu_{d} \\
\operatorname{Var}\left(\Delta d_{t+1}\right)=\phi^{2} \frac{\varphi_{e}^{2} \sigma^{2}}{1-\rho^{2}}+\sigma^{2} \varphi_{d}^{2} \\
\operatorname{Cov}\left(\Delta d_{t+1}, \Delta d_{t+2}\right)=\phi^{2} \rho \frac{\varphi_{e}^{2} \sigma^{2}}{1-\rho^{2}}
\end{gathered}
$$

Also, from the consumption and dividend growth processes,

$$
\operatorname{Cov}\left(\Delta c_{t+1}, \Delta d_{t+1}\right)=\phi \frac{\varphi_{e}^{2} \sigma^{2}}{1-\rho^{2}}
$$

Finally, we have

$$
\operatorname{Var}\left(\left(\Delta c_{t+1}\right)^{2}\right)=E\left[\operatorname{Var}_{t}\left(\left(\Delta c_{t+1}\right)^{2}\right)\right]+\operatorname{Var}\left[E_{t}\left(\left(\Delta c_{t+1}\right)^{2}\right)\right]
$$

Now,

$$
\left(\Delta c_{t+1}\right)^{2}=\mu^{2}+x_{t}^{2}+\sigma_{t}^{2} \eta_{t+1}^{2}+2 \mu x_{t}+2 x_{t} \sigma_{t} \eta_{t+1}+2 \mu \sigma_{t} \eta_{t+1}
$$

Hence, 


$$
E_{t}\left(\left(\Delta c_{t+1}\right)^{2}\right)=\mu^{2}+x_{t}^{2}+\sigma_{t}^{2}+2 \mu x_{t}
$$

$$
\begin{aligned}
\operatorname{Var}\left[E_{t}\left(\left(\Delta c_{t+1}\right)^{2}\right)\right]= & \operatorname{Var}\left(x_{t}^{2}\right)+\operatorname{Var}\left(\sigma_{t}^{2}\right)+4 \mu^{2} \operatorname{Var}\left(x_{t}\right)+4 \mu \operatorname{Cov}\left(x_{t}, x_{t}^{2}\right) \\
& +2 \operatorname{Cov}\left(x_{t}^{2}, \sigma_{t}^{2}\right)+4 \mu \operatorname{Cov}\left(x_{t}, \sigma_{t}^{2}\right)
\end{aligned}
$$
and

Now, $\operatorname{Var}\left(\sigma_{t}^{2}\right)=\frac{\sigma_{w}^{2}}{1-v^{2}}, \operatorname{Cov}\left(x_{t}, \sigma_{t}^{2}\right)=0, \operatorname{Cov}\left(x_{t}^{2}, \sigma_{t}^{2}\right)=\frac{\varphi_{e}^{2} \sigma_{w}^{2} v}{\left(1-v^{2}\right)\left(1-v \rho^{2}\right)}, \operatorname{Cov}\left(x_{t}, x_{t}^{2}\right)=0$,

$$
\operatorname{Var}\left(x_{t}^{2}\right)=\frac{3 \varphi_{e}^{4} \sigma_{w}^{2}\left(1+v \rho^{2}\right)}{\left(1-\rho^{4}\right)\left(1-v^{2}\right)\left(1-v \rho^{2}\right)}+\frac{1}{1-\rho^{4}}\left[2 \sigma^{4}+\frac{4 \rho^{2} \varphi_{e}^{4} \sigma^{4}}{\left(1-\rho^{2}\right)}\right]
$$

Substituting the above expressions into equation (), we have

$$
\begin{aligned}
\operatorname{Var}\left[E_{t}\left(\left(\Delta c_{t+1}\right)^{2}\right)\right]= & \frac{3 \varphi_{e}^{4} \sigma_{w}^{2}\left(1+v \rho^{2}\right)}{\left(1-\rho^{4}\right)\left(1-v^{2}\right)\left(1-v \rho^{2}\right)}+\frac{1}{1-\rho^{4}}\left[2 \sigma^{4}+\frac{4 \rho^{2} \varphi_{e}^{4} \sigma^{4}}{\left(1-\rho^{2}\right)}\right] \\
& +\frac{\sigma_{w}^{2}}{1-v^{2}}+4 \mu^{2} \frac{\varphi_{e}^{2} \sigma^{2}}{1-\rho^{2}}+\frac{2 \varphi_{e}^{2} \sigma_{w}^{2} v}{\left(1-v^{2}\right)\left(1-v \rho^{2}\right)}
\end{aligned}
$$

Also, from equation (11),

$$
\operatorname{Var}_{t}\left(\left(\Delta c_{t+1}\right)^{2}\right)=2 \sigma_{t}^{4}+4 x_{t}^{2} \sigma_{t}^{2}+4 \mu^{2} \sigma_{t}^{2}+8 \mu x_{t} \sigma_{t}^{2}
$$

Hence,

$$
E\left[\operatorname{Var}_{t}\left(\left(\Delta c_{t+1}\right)^{2}\right)\right]=2 \frac{\sigma_{w}^{2}}{1-v^{2}}+2 \sigma^{4}+\frac{4 \varphi_{e}^{2} \sigma_{w}^{2} v}{\left(1-v^{2}\right)\left(1-v \rho^{2}\right)}+\frac{4 \varphi_{e}^{2} \sigma^{4}}{1-\rho^{2}}+4 \mu^{2} \sigma^{2}
$$

Substituting equations (33) and (34) into equation (32), we have

$$
\begin{aligned}
\operatorname{Var}\left(\left(\Delta c_{t+1}\right)^{2}\right)= & \left.\frac{3 \varphi_{e}^{4} \sigma_{w}^{2}\left(1+v \rho^{2}\right)}{\left(1-\rho^{4}\right)\left(1-v^{2}\right)\left(1-v \rho^{2}\right)}+\frac{1}{1-\rho^{4}}\left[2 \sigma^{4}+\frac{4 \rho^{2} \varphi_{e}^{4} \sigma^{4}}{\left(1-\rho^{2}\right)}\right]+\frac{3 \sigma_{\varphi_{35}}^{2}}{1-v^{2}}\right) \\
& +4 \mu^{2} \frac{\varphi_{e}^{2} \sigma^{2}}{1-\rho^{2}}+\frac{6 \varphi_{e}^{2} \sigma_{w}^{2} v}{\left(1-v^{2}\right)\left(1-v \rho^{2}\right)}+\frac{4 \varphi_{e}^{2} \sigma^{4}}{1-\rho^{2}}+2 \sigma^{4}+4 \mu^{2} \sigma^{2}
\end{aligned}
$$

Similar calculations yield,

$$
\begin{aligned}
\operatorname{Var}\left[E_{t}\left(\left(\Delta d_{t+1}\right)^{2}\right)\right]= & \phi^{4}\left[\frac{3 \varphi_{e}^{4} \sigma_{w}^{2}\left(1+v \rho^{2}\right)}{\left(1-\rho^{4}\right)\left(1-v^{2}\right)\left(1-v \rho^{2}\right)}+\frac{1}{1-\rho^{4}}\left(2 \sigma^{4}+\frac{4 \rho^{2} \varphi_{e}^{4} \sigma^{4}}{\left(1-\rho^{2}\right)}\right)\right] \\
& +\frac{\sigma_{w}^{2}}{1-v^{2}} \varphi_{d}^{4}+4 \mu^{2} \frac{\varphi_{e}^{2} \sigma^{2}}{1-\rho^{2}} \phi^{2}+\frac{2 \varphi_{e}^{2} \sigma_{w}^{2} v}{\left(1-v^{2}\right)\left(1-v \rho^{2}\right)} \phi^{2} \varphi_{d}^{2}
\end{aligned}
$$




$$
\begin{aligned}
E\left[\operatorname{Var}_{t}\left(\left(\Delta d_{t+1}\right)^{2}\right)\right]= & {\left[2 \frac{\sigma_{w}^{2}}{1-v^{2}}+2 \sigma^{4}\right] \varphi_{d}^{4}+\left[\frac{4 \varphi_{e}^{2} \sigma_{w}^{2} v}{\left(1-v^{2}\right)\left(1-v \rho^{2}\right)}+\frac{4 \varphi_{e}^{2} \sigma^{4}}{1-\rho^{2}}\right] \phi^{2} \varphi_{d}^{2} } \\
& +4 \mu_{d}^{2} \varphi_{d}^{2} \sigma^{2}
\end{aligned}
$$

Hence, we have

$$
\begin{aligned}
\operatorname{Var}\left(\left(\Delta d_{t+1}\right)^{2}\right)= & \phi^{4}\left[\frac{3 \varphi_{e}^{4} \sigma_{w}^{2}\left(1+v \rho^{2}\right)}{\left(1-\rho^{4}\right)\left(1-v^{2}\right)\left(1-v \rho^{2}\right)}+\frac{1}{1-\rho^{4}}\left(2 \sigma^{4}+\frac{4 \rho^{2} \varphi_{e}^{4} \sigma^{4}}{\left(1-\rho^{2}\right)}\right)\right]+\frac{3 \sigma_{w}^{2}}{1-v^{2}} \varphi_{d}^{4} \\
& +4 \mu^{2} \frac{\varphi_{e}^{2} \sigma^{2}}{1-\rho^{2}} \phi^{2}+\frac{6 \varphi_{e}^{2} \sigma_{w}^{2} v}{\left(1-v^{2}\right)\left(1-v \rho^{2}\right)} \phi^{2} \varphi_{d}^{2}+\frac{4 \varphi_{e}^{2} \sigma^{4}}{1-\rho^{2}} \phi^{2} \varphi_{d}^{2} \\
& +2 \sigma^{4} \varphi_{d}^{4}+4 \mu_{d}^{2} \varphi_{d}^{2} \sigma^{2}
\end{aligned}
$$

Equations (25)-(31), (35), and (36) give 9 moments restrictions in the 9 time-series parameters.

\section{A.3 Estimation Methodology for Extended Model}

The model is given by the equations

$$
\begin{aligned}
\Delta c_{t+1} & =\mu_{c}+x_{t}+\sigma_{t} z_{c, t+1} \\
x_{t+1} & =\rho_{x} x_{t}+\psi_{x} \sigma_{t} z_{x, t+1} \\
\sigma_{t+1}^{2} & =\mu_{\sigma}+\rho_{\sigma} \sigma_{t}^{2}+\sigma_{w} z_{\sigma, t+1} \\
d_{t}-c_{t} & =\mu_{d c}+s_{t} \\
s_{t+1} & =\lambda_{s x} x_{t}+\rho_{s} s_{t}+\psi_{s} \sigma_{t} z_{s, t+1} \\
\Delta d_{t+1} & =\mu_{c}+\left(1+\lambda_{s x}\right) x_{t}+\left(\rho_{s}-1\right) s_{t}+\sigma_{t} z_{c, t+1}+\psi_{s} \sigma_{t} z_{s, t+1}
\end{aligned}
$$

Now, with Epstein and Zin (1989) preferences, for any asset $j$, the first-order conditions of a representative agent's utility maximization problem in an uncertain environment yields the following asset pricing Euler condition,

$$
E_{t}\left[\exp \left(m_{t+1}+r_{j, t+1}\right)\right]=1
$$

where $m_{t+1}$ is the natural logarithm of the intertemporal marginal rate of substitution and $r_{j, t+1}$ is the log of the gross return on asset $j$. Also,

$$
m_{t+1}=\theta \log \delta-\frac{\theta}{\psi} \Delta c_{t+1}+(\theta-1) r_{c, t+1}
$$


where $r_{c, t+1}$ is the unobservable log gross return on an asset that delivers aggregate consumption as its dividends each period.

Using the log-affine approximation for the continuous return on the consumption claim, $r_{c, t+1}$, and that on the market portfolio (the return on the aggregate dividend claim), $r_{m, t+1}$, as in Campbell and Shiller (1988),

$$
\begin{aligned}
r_{c, t+1} & =\kappa_{0}+\kappa_{1} z_{t+1}-z_{t}+\Delta c_{t+1} \\
r_{m, t+1} & =\kappa_{0, m}+\kappa_{1, m} z_{m, t+1}-z_{m, t}+\Delta d_{t+1}
\end{aligned}
$$

where $z_{t}$ and $z_{m, t}$ are the log price-dividend ratios of the consumption and the dividend claims respectively, and conjecturing that these ratios are affine functions of the state variables, $x_{t}, \sigma_{t}^{2}$, and $s_{t}$,

$$
\begin{aligned}
z_{t} & =A_{0}+A_{1} x_{t}+A_{2} \sigma_{t}^{2}+A_{3} s_{t} \\
z_{m, t} & =A_{0, m}+A_{1, m} x_{t}+A_{2, m} \sigma_{t}^{2}+A_{3, m} s_{t}
\end{aligned}
$$

the coefficients $A_{0}, A_{1}, A_{2}, A_{3}, A_{0, m}, A_{1, m}, A_{2, m}, A_{3, m}$ may be computed using methods similar to those in Bansal and Yaron (2004) and Tauchen (2005).

\section{A.3.1 The Consumption Claim}

From equations () and (), for the unobservable return on the consumption claim, $r_{c, t+1}$, the Euler equation is,

$$
E_{t}\left[\exp \left(\theta \log \delta-\frac{\theta}{\psi} \Delta c_{t+1}+\theta r_{c, t+1}\right)\right]=1
$$

Substituting the expression for $r_{c, t+1}$ from equation () into the above Euler condition and noting that $z_{t}$ is given by equation (), we have

$$
\begin{aligned}
& E_{t}\left[\operatorname { e x p } \left(\theta \log \delta-\frac{\theta}{\psi} \mu_{c}-\frac{\theta}{\psi} x_{t}-\frac{\theta}{\psi} \sigma_{t} z_{c, t+1}+\theta \kappa_{0}+\theta \kappa_{1} A_{0}\right.\right. \\
& +\theta \kappa_{1} A_{1} \rho_{x} x_{t}+\theta \kappa_{1} A_{1} \psi_{x} \sigma_{t} z_{x, t+1}+\theta \kappa_{1} A_{2} \mu_{\sigma}+\theta \kappa_{1} A_{2} \rho_{\sigma} \sigma_{t}^{2}+\theta \kappa_{1} A_{2} \sigma_{w} z_{\sigma, t+1} \\
& +\theta \kappa_{1} A_{3} \lambda_{s x} x_{t}+\theta \kappa_{1} A_{3} \rho_{s} s_{t}+\theta \kappa_{1} A_{3} \psi_{s} \sigma_{t} z_{s, t+1}-\theta A_{0}-\theta A_{1} x_{t}-\theta A_{2} \sigma_{t}^{2}-\theta A_{3} s_{t} \\
& \left.\left.+\theta \mu_{c}+\theta x_{t}+\theta \sigma_{t} z_{c, t+1}\right)\right] \\
& =1
\end{aligned}
$$

Using the assumed conditional log-normality of the stochastic processes, the above expression implies 


$$
\begin{array}{ll}
\exp (\quad & \theta \log \delta+\left(-\frac{\theta}{\psi}+\theta\right) \mu_{c}+\theta \kappa_{0}+\theta\left(\kappa_{1}-1\right) A_{0}+\theta \kappa_{1} A_{2} \mu_{\sigma} \\
+ & {\left[-\frac{\theta}{\psi}+\theta+\theta\left(\kappa_{1} \rho_{x}-1\right) A_{1}+\theta \kappa_{1} A_{3} \lambda_{s x}\right] x_{t}} \\
& +\theta\left(\kappa_{1} \rho_{s}-1\right) A_{3} s_{t}+\theta\left(\kappa_{1} \rho_{\sigma}-1\right) A_{2} \sigma_{t}^{2} \\
& \left.+0.5\left\{\left(-\frac{\theta}{\psi}+\theta\right)^{2} \sigma_{t}^{2}+\left(\theta \kappa_{1} A_{1} \psi_{x}\right)^{2} \sigma_{t}^{2}+\left(\theta \kappa_{1} A_{2} \sigma_{w}\right)^{2}\right\}\right) \\
= & 1
\end{array}
$$

Since the Euler equation must hold for all values of the state variables, we have

$$
\theta\left(\kappa_{1} \rho_{s}-1\right) A_{3}=0
$$

Hence,

$$
A_{3}=0
$$

Similarly,

$$
-\frac{\theta}{\psi}+\theta+\theta\left(\kappa_{1} \rho_{x}-1\right) A_{1}+\theta \kappa_{1} A_{3} \lambda_{s x}=0
$$

implying

$$
A_{1}=\frac{1-\frac{1}{\psi}}{1-\kappa_{1} \rho_{x}}
$$

and

$$
\begin{gathered}
\theta\left(\kappa_{1} \rho_{\sigma}-1\right) A_{2}+0.5\left\{\left(-\frac{\theta}{\psi}+\theta\right)^{2}+\left(\theta \kappa_{1} A_{1} \psi_{x}\right)^{2}\right\}=0 \\
A_{2}=\frac{0.5\left[\left(-\frac{\theta}{\psi}+\theta\right)^{2}+\left(\theta \kappa_{1} A_{1} \psi_{x}\right)^{2}\right]}{\theta\left(1-\kappa_{1} \rho_{\sigma}\right)} \\
\theta \log \delta+\left(-\frac{\theta}{\psi}+\theta\right) \mu_{c}+\theta \kappa_{0}+\theta\left(\kappa_{1}-1\right) A_{0}+\theta \kappa_{1} A_{2} \mu_{\sigma}+0.5\left(\theta \kappa_{1} A_{2} \sigma_{w}\right)^{2}=0 \\
A_{0}=\frac{\log \delta+\left(-\frac{1}{\psi}+1\right) \mu_{c}+\kappa_{0}+\kappa_{1} A_{2} \mu_{\sigma}+0.5 \theta\left(\kappa_{1} A_{2} \sigma_{w}\right)^{2}}{1-\kappa_{1}}
\end{gathered}
$$




\section{A.3.2 The Dividend Claim}

The Euler equation for the observable return on the aggregate dividend claim, $r_{m, t+1}$, is,

$$
E_{t}\left[\exp \left(\theta \log \delta-\frac{\theta}{\psi} \Delta c_{t+1}+(\theta-1) r_{c, t+1}+r_{m, t+1}\right)\right]=1
$$

Substituting the expression for $r_{m, t+1}$ from equation () into the above Euler condition and noting that $z_{m, t}$ is given by equation (), we have

$$
\begin{aligned}
& E_{t}\left[\operatorname { e x p } \left(\theta \log \delta-\frac{\theta}{\psi} \mu_{c}-\frac{\theta}{\psi} x_{t}-\frac{\theta}{\psi} \sigma_{t} z_{c, t+1}+(\theta-1) \kappa_{0}+(\theta-1) \kappa_{1} A_{0}\right.\right. \\
& +(\theta-1) \kappa_{1} A_{1} \rho_{x} x_{t}+(\theta-1) \kappa_{1} A_{1} \psi_{x} \sigma_{t} z_{x, t+1} \\
& +(\theta-1) \kappa_{1} A_{2} \mu_{\sigma}+(\theta-1) \kappa_{1} A_{2} \rho_{\sigma} \sigma_{t}^{2}+(\theta-1) \kappa_{1} A_{2} \sigma_{w} z_{\sigma, t+1} \\
& +(\theta-1) \kappa_{1} A_{3} \lambda_{s x} x_{t}+(\theta-1) \kappa_{1} A_{3} \rho_{s} s_{t}+(\theta-1) \kappa_{1} A_{3} \psi_{s} \sigma_{t} z_{s, t+1} \\
& -(\theta-1) A_{0}-(\theta-1) A_{1} x_{t}-(\theta-1) A_{2} \sigma_{t}^{2}-(\theta-1) A_{3} s_{t} \\
& +(\theta-1) \mu_{c}+(\theta-1) x_{t}+(\theta-1) \sigma_{t} z_{c, t+1} \\
& +\kappa_{0, m}+\kappa_{1, m} A_{0, m}+\kappa_{1, m} A_{1, m} \rho_{x} x_{t}+\kappa_{1, m} A_{1, m} \psi_{x} \sigma_{t} z_{x, t+1}+\kappa_{1, m} A_{2, m} \mu_{\sigma} \\
& +\kappa_{1, m} A_{2, m} \rho_{\sigma} \sigma_{t}^{2}+\kappa_{1, m} A_{2, m} \sigma_{w} z_{\sigma, t+1}+\kappa_{1, m} A_{3, m} \lambda_{s x} x_{t}+\kappa_{1, m} A_{3, m} \rho_{s} s_{t} \\
& +\kappa_{1, m} A_{3, m} \psi_{s} \sigma_{t} z_{s, t+1}-A_{0, m}-A_{1, m} x_{t}-A_{2, m} \sigma_{t}^{2}-A_{3, m} s_{t} \\
& \left.\left.+\mu_{c}+\left(1+\lambda_{s x}\right) x_{t}+\left(\rho_{s}-1\right) s_{t}+\sigma_{t} z_{c, t+1}+\psi_{s} \sigma_{t} z_{s, t+1}\right)\right] \\
& =1
\end{aligned}
$$

Using the assumed conditional log-normality of the stochastic processes, the above expression implies

$$
\begin{aligned}
\exp (\quad & \theta \log \delta+\left(-\frac{\theta}{\psi}+\theta\right) \mu_{c}+(\theta-1) \kappa_{0}+(\theta-1)\left(\kappa_{1}-1\right) A_{0}+(\theta-1) \kappa_{1} A_{2} \mu_{\sigma} \\
& +\kappa_{0, m}+\left(\kappa_{1, m}-1\right) A_{0, m}+\kappa_{1, m} A_{2, m} \mu_{\sigma} \\
+ & {\left[\left(-\frac{\theta}{\psi}+\theta-1\right)+(\theta-1)\left(\kappa_{1} \rho_{x}-1\right) A_{1}+(\theta-1) \kappa_{1} A_{3} \lambda_{s x}+\left(\kappa_{1, m} \rho_{x}-1\right) A_{1, m}+\left(1+\lambda_{s x}\right)\right] } \\
& +\left[\kappa_{1, m} A_{3, m} \lambda_{s x}\right] x_{t}+\left[(\theta-1)\left(\kappa_{1} \rho_{s}-1\right) A_{3}+\left(\kappa_{1, m} \rho_{s}-1\right) A_{3, m}+\rho_{s}-1\right] s_{t} \\
& +\left[(\theta-1)\left(\kappa_{1} \rho_{\sigma}-1\right) A_{2}+\left(\kappa_{1, m} \rho_{\sigma}-1\right) A_{2, m}\right] \sigma_{t}^{2} \\
& +0.5\left\{\left(-\frac{\theta}{\psi}+\theta\right)^{2} \sigma_{t}^{2}+\left[(\theta-1) \kappa_{1} A_{3}+\kappa_{1, m} A_{3, m}+1\right]^{2} \psi_{s}^{2} \sigma_{t}^{2}\right. \\
& \left.\left.+\left[(\theta-1) \kappa_{1} A_{1}+\kappa_{1, m} A_{1, m}\right]^{2} \psi_{x}^{2} \sigma_{t}^{2}+\left[(\theta-1) \kappa_{1} A_{2}+\kappa_{1, m} A_{2, m}\right]^{2} \sigma_{w}^{2}\right\}\right) \\
= & 1
\end{aligned}
$$


Since the Euler equation must hold for all values of the state variables, we have

$$
\begin{aligned}
& {\left[(\theta-1)\left(\kappa_{1} \rho_{s}-1\right) A_{3}+\left(\kappa_{1, m} \rho_{s}-1\right) A_{3, m}+\rho_{s}-1\right]=0} \\
& A_{3, m}=\frac{\rho_{s}-1}{1-\kappa_{1, m} \rho_{s}} \\
& \left(-\frac{\theta}{\psi}+\theta-1\right)+(\theta-1)\left(\kappa_{1} \rho_{x}-1\right) A_{1}+(\theta-1) \kappa_{1} A_{3} \lambda_{s x}+\left(\kappa_{1, m} \rho_{x}-1\right) A_{1, m}+\kappa_{1, m} A_{3, m} \lambda_{s x}+1+\lambda_{s x}=0 \\
& A_{1, m}=\frac{1-\frac{1}{\psi}+\lambda_{s x}\left(1+\kappa_{1, m} A_{3, m}\right)}{1-\kappa_{1, m} \rho_{x}} \\
& (\theta-1)\left(\kappa_{1} \rho_{\sigma}-1\right) A_{2}+\left(\kappa_{1, m} \rho_{\sigma}-1\right) A_{2, m}+0.5\left\{\left(-\frac{\theta}{\psi}+\theta\right)^{2}\right. \\
& \left.+\left[(\theta-1) \kappa_{1} A_{3}+\kappa_{1, m} A_{3, m}+1\right]^{2} \psi_{s}^{2}+\left[(\theta-1) \kappa_{1} A_{1}+\kappa_{1, m} A_{1, m}\right]^{2} \psi_{x}^{2}\right\} \\
& =0 \\
& \begin{aligned}
A_{2, m}= & \frac{(\theta-1)\left(\kappa_{1} \rho_{\sigma}-1\right) A_{2}+C}{1-\kappa_{1, m} \rho_{\sigma}} \\
C= & 0.5\left\{\left(-\frac{\theta}{\psi}+\theta\right)^{2}+\left[\kappa_{1, m} A_{3, m}+1\right]^{2} \psi_{s}^{2}\right. \\
& \left.+\left[(\theta-1) \kappa_{1} A_{1}+\kappa_{1, m} A_{1, m}\right]^{2} \psi_{x}^{2}\right\}
\end{aligned} \\
& \theta \log \delta+\left(-\frac{\theta}{\psi}+\theta\right) \mu_{c}+(\theta-1) \kappa_{0}+(\theta-1)\left(\kappa_{1}-1\right) A_{0}+(\theta-1) \kappa_{1} A_{2} \mu_{\sigma} \\
& +\kappa_{0, m}+\left(\kappa_{1, m}-1\right) A_{0, m}+\kappa_{1, m} A_{2, m} \mu_{\sigma}+0.5\left[(\theta-1) \kappa_{1} A_{2}+\kappa_{1, m} A_{2, m}\right]^{2} \sigma_{w}^{2} \\
& =0 \\
& A_{0, m}=\frac{\theta \log \delta+\left(-\frac{\theta}{\psi}+\theta\right) \mu_{c}+(\theta-1) \kappa_{0}+(\theta-1)\left(\kappa_{1}-1\right) A_{0}}{1-\kappa_{1, m}} \\
& +\frac{(\theta-1) \kappa_{1} A_{2} \mu_{\sigma}+\kappa_{0, m}+\kappa_{1, m} A_{2, m} \mu_{\sigma}+0.5\left[(\theta-1) \kappa_{1} A_{2}+\kappa_{1, m} A_{2, m}\right]^{2} \sigma_{w}^{2}}{1-\kappa_{1, m}}
\end{aligned}
$$




\section{A.3.3 The Risk Free Rate}

To derive the expression for the risk free rate, note that

$$
E_{t}\left[\exp \left(\theta \log \delta-\frac{\theta}{\psi} \Delta c_{t+1}+(\theta-1) r_{c, t+1}+r_{f, t}\right)\right]=1
$$

Hence,

$$
\begin{aligned}
\exp \left(-r_{f, t}\right)= & E_{t}\left[\exp \left(\theta \log \delta-\frac{\theta}{\psi} \Delta c_{t+1}+(\theta-1) r_{c, t+1}\right)\right] \\
= & \exp \left(\theta \log \delta-\frac{\theta}{\psi} \mu_{c}-\frac{\theta}{\psi} x_{t}\right. \\
& +(\theta-1) \kappa_{0}+(\theta-1) \kappa_{1} A_{0}+(\theta-1) \kappa_{1} A_{1} \rho_{x} x_{t}+(\theta-1) \kappa_{1} A_{2} \mu_{\sigma} \\
& +(\theta-1) \kappa_{1} A_{2} \rho_{\sigma} \sigma_{t}^{2}+(\theta-1) \kappa_{1} A_{3} \lambda_{s x} x_{t}+(\theta-1) \kappa_{1} A_{3} \rho_{s} s_{t} \\
& -(\theta-1) A_{0}-(\theta-1) A_{1} x_{t}-(\theta-1) A_{2} \sigma_{t}^{2}-(\theta-1) A_{3} s_{t} \\
& +(\theta-1) \mu_{c}+(\theta-1) x_{t} \\
& \left.+0.5\left[\left(-\frac{\theta}{\psi}+\theta-1\right)^{2} \sigma_{t}^{2}++(\theta-1)^{2} \kappa_{1}^{2} A_{1}^{2} \psi_{x}^{2} \sigma_{t}^{2}+(\theta-1)^{2} \kappa_{1}^{2} A_{2}^{2} \sigma_{w}^{2}\right]\right)
\end{aligned}
$$

Therefore, the risk free rate is

$$
\begin{aligned}
r_{f, t}= & -\theta \log \delta-\left(-\frac{\theta}{\psi}+\theta-1\right) \mu_{c}-(\theta-1) \kappa_{0}-(\theta-1)\left(\kappa_{1}-1\right) A_{0}-(\theta-1) \kappa_{1} A_{2} \mu_{\sigma} \\
& -0.5(\theta-1)^{2} \kappa_{1}^{2} A_{2}^{2} \sigma_{w}^{2}-\left[\left(-\frac{\theta}{\psi}+\theta-1\right)+(\theta-1)\left(\kappa_{1} \rho_{x}-1\right) A_{1}\right] x_{t} \\
& -\left[(\theta-1)\left(\kappa_{1} \rho_{s}-1\right) A_{3}\right] s_{t}+ \\
& -\left[(\theta-1)\left(\kappa_{1} \rho_{\sigma}-1\right) A_{2}+0.5\left\{\left(-\frac{\theta}{\psi}+\theta-1\right)^{2}+(\theta-1)^{2} \kappa_{1}^{2} A_{1}^{2} \psi_{x}^{2}\right\}\right] \sigma_{t}^{2} \\
= & A_{0, f}+A_{1, f} x_{t}+A_{2, f} \sigma_{t}^{2}
\end{aligned}
$$

\section{A.3.4 Latent State Variables in terms of Observable Variables}

We have

$$
\begin{aligned}
z_{m, t} & =A_{0, m}+A_{1, m} x_{t}+A_{2, m} \sigma_{t}^{2}+A_{3, m} s_{t} \\
r_{f, t} & =A_{0, f}+A_{1, f} x_{t}+A_{2, f} \sigma_{t}^{2}
\end{aligned}
$$


The above equations may be inverted to express the unobservable state variables $x_{t}, \sigma_{t}^{2}$, and $s_{t}$ in terms of the observables $z_{m, t}, r_{f, t}$, and $s_{t}$.

Define,

$$
D \equiv A_{1, m} A_{2, f}-A_{1, f} A_{2, m}
$$

We have,

$$
\begin{aligned}
x_{t} & =\alpha_{0}+\alpha_{1} r_{f, t}+\alpha_{2} z_{m, t}+\alpha_{3} s_{t} \\
\alpha_{0} & =\frac{A_{0, f} A_{2, m}-A_{0, m} A_{2, f}}{D} \\
\alpha_{1} & =\frac{-A_{2, m}}{D} \\
\alpha_{2} & =\frac{A_{2, f}}{D} \\
\alpha_{3} & =\frac{-A_{3, m} A_{2, f}}{D} \\
\sigma_{t}^{2} & =\beta_{0}+\beta_{1} r_{f, t}+\beta_{2} z_{m, t}+\beta_{3} z_{v-g, t} \\
\beta_{0} & =\frac{A_{0, m} A_{1, f}-A_{1, m} A_{0, f}}{D} \\
\beta_{1} & =\frac{A_{1, m}}{D} \\
\beta_{2} & =\frac{-A_{1, f}}{D} \\
\beta_{3} & =\frac{A_{1, f} A_{3, m}}{D}
\end{aligned}
$$

Now, from equations (10) and (11), the pricing kernel is given by the expression

$$
\begin{aligned}
m_{t+1}= & \left(\theta \log \delta+(\theta-1)\left[\kappa_{0}+\left(\kappa_{1}-1\right) A_{0}\right]\right)+\left(-\frac{\theta}{\psi}+(\theta-1)\right) \Delta c_{t+1} \\
& +(\theta-1) \kappa_{1} A_{1} x_{t+1}+(\theta-1) \kappa_{1} A_{2} \sigma_{t+1}^{2} \\
& -(\theta-1) A_{1} x_{t}-(\theta-1) A_{2} \sigma_{t}^{2}
\end{aligned}
$$

Substituting the expressions for $x_{t}, \sigma_{t}^{2}$, and $s_{t}$ into the pricing kernel above, we have

$$
\begin{aligned}
m_{t+1} & =c_{1}+c_{2} \Delta c_{t+1}+c_{3} r_{f, t+1}+c_{4} z_{m, t+1}+c_{5} s_{t+1}+c_{6} r_{f, t}+c_{7} z_{m, t}+c_{8} s_{t} \\
& \approx c_{1}+c_{2} \Delta c_{t+1}+c_{3}\left(r_{f, t+1}-r_{f, t}\right)+c_{4}\left(z_{m, t+1}-z_{m, t}\right)+c_{5}\left(s_{t+1}-s_{t}\right)
\end{aligned}
$$


where

$$
\begin{aligned}
& c_{1}=\theta \log \delta+(\theta-1)\left[\kappa_{0}+\left(\kappa_{1}-1\right) A_{0}\right] \\
& c_{2}=-\frac{\theta}{\psi}+(\theta-1) \\
& c_{3}=(\theta-1) \kappa_{1}\left[A_{1} \alpha_{2}+A_{2} \beta_{1}\right] \\
& c_{4}=(\theta-1) \kappa_{1}\left[A_{1} \alpha_{2}+A_{2} \beta_{2}\right] \\
& c_{5}=(\theta-1) \kappa_{1}\left[A_{1} \alpha_{3}+A_{2} \beta_{3}\right]
\end{aligned}
$$

\section{A.4 Estimation of Time-Series Parameters of the Extended Model}

In this specification, there are 10 parameters to be estimated $-\mu, \mu_{d c}, \rho_{x}, \varphi_{e}, \sigma, v$, $\sigma_{w}, \lambda_{s x}, \rho_{s}, \psi_{s}$. The two parameters of the stochastic volatility process, namely, $v$ and $\sigma_{w}$, are quite imprecisely estimated and, hence, are set to values 0.994 and $0.23 \times 10^{-5}$, respectively.

The specification of the consumption growth process is the same as in Bansal and Yaron (2004). Hence, we have

$$
\begin{gathered}
E\left(\Delta c_{t+1}\right)=\mu \\
\operatorname{Var}\left(\Delta c_{t+1}\right)=\operatorname{Var}\left(x_{t}\right)+\operatorname{Var}\left(\sigma_{t} \eta_{t+1}\right)+2 \operatorname{Cov}\left(x_{t}, \sigma_{t} \eta_{t+1}\right) \\
=\operatorname{Var}\left(x_{t}\right)+\sigma^{2}+0 \\
=\frac{\varphi_{e}^{2} \sigma^{2}}{1-\rho_{x}^{2}}+\sigma^{2}
\end{gathered}
$$

and,

$$
\begin{aligned}
\operatorname{Cov}\left(\Delta c_{t+1}, \Delta c_{t+2}\right) & =\rho_{x} \frac{\varphi_{e}^{2} \sigma^{2}}{1-\rho_{x}^{2}} \\
\operatorname{Cov}\left(\Delta c_{t+1}, \Delta c_{t+3}\right) & =\rho_{x}^{2} \frac{\varphi_{e}^{2} \sigma^{2}}{1-\rho_{x}^{2}}
\end{aligned}
$$

From the specification of the dividend growth process, we have 


$$
\begin{aligned}
\operatorname{Var}\left(\Delta d_{t+1}\right)= & \left(1+\lambda_{s x}\right)^{2} \operatorname{Var}\left(x_{t}\right)+\left(\rho_{s}-1\right)^{2} \operatorname{Var}\left(s_{t}\right)+ \\
& \left(1+\psi_{s}^{2}\right) \sigma^{2}+2\left(1+\lambda_{s x}\right)\left(\rho_{s}-1\right) \operatorname{Cov}\left(x_{t}, s_{t}\right)
\end{aligned}
$$

where $\operatorname{Var}\left(x_{t}\right)=\frac{\varphi_{e}^{2} \sigma^{2}}{1-\rho^{2}}, \operatorname{Cov}\left(x_{t}, s_{t}\right)=\frac{\lambda_{s x} \rho_{x}}{1-\rho_{x} \rho_{s}} \operatorname{Var}\left(x_{t}\right)$, and

$$
\operatorname{Var}\left(s_{t}\right)=\frac{\lambda_{s x}^{2} \operatorname{Var}\left(x_{t}\right)+\psi_{s}^{2} \sigma^{2}+\frac{2 \lambda_{s x}^{2} \rho_{x} \rho_{s} \operatorname{Var}\left(x_{t}\right)}{1-\rho_{x} \rho_{s}}}{1-\rho_{s}^{2}}
$$

Also,

$$
\begin{aligned}
\operatorname{Cov}\left(\Delta d_{t+1}, \Delta d_{t+2}\right)= & \left(1+\lambda_{s x}\right)^{2} \operatorname{Cov}\left(x_{t+1}, x_{t}\right)+\left(\rho_{s}-1\right)^{2} \operatorname{Cov}\left(s_{t+1}, s_{t}\right) \\
& +\left(1+\lambda_{s x}\right)\left(\rho_{s}-1\right)\left[\operatorname{Cov}\left(x_{t+1}, s_{t}\right)+\operatorname{Cov}\left(x_{t}, s_{t+1}\right)\right] \\
& +\left(\rho_{s}-1\right) \psi_{s} \operatorname{Cov}\left(s_{t+1}, \sigma_{t} z_{s, t+1}\right)
\end{aligned}
$$

where $\operatorname{Cov}\left(x_{t+1}, x_{t}\right)=\rho_{x} \operatorname{Var}\left(x_{t}\right), \operatorname{Cov}\left(s_{t+1}, s_{t}\right)=\lambda_{s x} \operatorname{Cov}\left(x_{t}, s_{t}\right)+\rho_{s} \operatorname{Var}\left(s_{t}\right)$, $\operatorname{Cov}\left(x_{t}, s_{t+1}\right)=\lambda_{s x} \operatorname{Var}\left(x_{t}\right)+\rho_{s} \operatorname{Cov}\left(x_{t}, s_{t}\right), \operatorname{Cov}\left(x_{t+1}, s_{t}\right)=\rho_{x} \operatorname{Cov}\left(x_{t}, s_{t}\right)$, and $\operatorname{Cov}\left(s_{t+1}, \sigma_{t} z_{s, t+1}\right)=$ $\psi_{s} \sigma^{2}$.

Finally,

$$
\operatorname{Cov}\left(\Delta c_{t+1}, \Delta d_{t+1}\right)=\left(1+\lambda_{s x}\right) \operatorname{Var}\left(x_{t}\right)+\left(\rho_{s}-1\right) \operatorname{Cov}\left(x_{t}, s_{t}\right)+\sigma^{2}
$$

and

$$
E\left(d_{t}-c_{t}\right)=\mu_{d c}
$$

Equations (58)-(65) give 8 moment restrictions in the 8 parameters $\mu, \mu_{d c}, \rho_{x}, \varphi_{e}$, $\sigma, \lambda_{s x}, \rho_{s}, \psi_{s}$ 
Table 1: Descriptive Statistics

\begin{tabular}{lcccccc} 
& \multicolumn{3}{c}{$\log ($ returns $)$} & \multicolumn{1}{c}{$\log (P / D)$} & \multicolumn{1}{c}{$\log \left(D_{t+1} / D_{t}\right)$} \\
\hline \multirow{2}{*}{$\begin{array}{l}\text { SizePortfolios } \\
\text { Small }\end{array}$} & 0.092 & 0.300 & 4.125 & 0.691 & 0.084 & 0.349 \\
\cline { 2 - 6 } Large & 0.062 & 0.173 & 3.323 & 0.444 & 0.010 & 0.130 \\
& & & & & & \\
B/M Portfolios & & & & & & \\
Growth & 0.057 & 0.202 & 3.732 & 0.631 & 0.011 & 0.205 \\
Value & 0.104 & 0.288 & 3.562 & 1.118 & 0.087 & 0.552 \\
& & & & & & \\
Market & 0.070 & 0.190 & 3.270 & 0.386 & 0.021 & 0.126 \\
Risk free rate & 0.007 & 0.055 & & & &
\end{tabular}

This table shows the descriptive statistics for the annual log returns, the log pricedividend ratios, and the log dividend growth rates of the market, the risk free rate, the "Small", "Large", "Growth", and "Value" portfolios. The sample period is 1930-2006. 
Table 2: Tests of the LRR Model on the 2-Asset System

\begin{tabular}{lcccc}
\hline & \multicolumn{3}{c}{ Panel A: identity weighting matrix } \\
\cline { 2 - 5 } Estimated & $c_{1}$ & $c_{2}$ & $c_{3}$ & $c_{4}$ \\
& -0.051 & -5.099 & -1.973 & -3.524 \\
Pr edicted & $(0.121)$ & $(7.358)$ & $(11.16)$ & $(1.391)$ \\
& -0.373 & -10.00 & -146.0 & -3.152 \\
Pricing Errors & \multicolumn{5}{c}{ Mean } & Std.Dev. \\
Market & \multicolumn{5}{c}{0.0004} & 0.517 \\
Risk free rate & \multicolumn{5}{c}{-0.0024} & 0.671 \\
J-stat & 0.001 & & \\
& $(>0.10)$ & \multicolumn{3}{c}{ Panel B: optimal weighting matrix } \\
\cline { 2 - 5 } & $c_{1}$ & $c_{2}$ & $c_{3}$ & $c_{4}$ \\
Estimated & -0.620 & 14.79 & -13.78 & -4.554 \\
Pr edicted & $(0.458)$ & $(13.82)$ & $(5.813)$ & $(1.465)$ \\
Pricing Errors & -0.373 & -10.00 & -146.0 & -3.152 \\
Market & \multicolumn{5}{c}{ Mean } & Std.Dev. \\
Risk free rate & \multicolumn{5}{c}{0.005} & 1.098 \\
J-stat & 0.677 & 0.008 & 1.188 \\
\hline \hline
\end{tabular}

$\overline{\text { The table reports GMM estimates of the Bansal and Yaron (2004) LRR }}$ Model. Panel A reports results for the identity weighting matrix while Panel B reports the same for the efficient weighting matrix. The pricing kernel is a function of the consumption growth, the difference in the log price-dividend ratio of the market and its lag, and the risk free rate and its lag. The asset menu consists of the market portfolio, and the risk free rate. The lagged pricedividend ratio of the market and the lagged risk free rate are used as instruments. The table presents the parameter estimates along with the associated standard errors in parentheses. Average pricing errors along with the standard deviation of the errors are presented for each asset. The bottom line in each Panel reports the J-statistic for the overidentifying restrictions along with the associated p-values in parentheses. The J-statistic has a nonstandard aymptotic distribution for the identity weighting matrix with $90 \%, 95 \%$, and $99 \%$ critical values given by $0.002,0.003$, and 0.004 respectively, and an asymptotic $\chi^{2}$-distribution with two degrees of freedom for the efficient weighting matrix. The data employed in the estimation are annual and cover the period 1930:2006. 
Table 3: Tests of the LRR Model on the 2-Asset System

\begin{tabular}{lcccc}
\hline & \multicolumn{3}{c}{ Panel A: identity weighting matrix } \\
\cline { 2 - 5 } Estimated & $c_{1}$ & $c_{2}$ & $c_{3}$ & $c_{4}$ \\
Pr edicted & -0.101 & -5.052 & -2.130 & -4.272 \\
& $(0.652)$ & $(57.05)$ & $(51.88)$ & $(6.548)$ \\
Pr icing Errors & -0.988 & -10.00 & -26.17 & -6.438 \\
Market & & Mean & Std.Dev. \\
Risk free rate & & -0.0003 & 0.6739 \\
J-stat & 0.0103 & -0.0066 & 0.8394 \\
& $(>0.10)$ & & \\
\hline
\end{tabular}

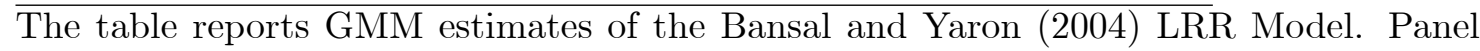
A reports results for the identity weighting matrix. The pricing kernel is a function of the consumption growth, the difference in the log price-dividend ratio of the market and its lag, and the risk free rate and its lag. The asset menu consists of the market portfolio, and the risk free rate. The lagged price-dividend ratio of the market and the lagged risk free rate are used as instruments. The table presents the parameter estimates along with the associated standard errors in parentheses. Average pricing errors along with the standard deviation of the errors are presented for each asset. The bottom line in the Panel reports the J-statistic for the overidentifying restrictions along with the associated p-values in parentheses. The J-statistic has a non-standard aymptotic distribution for the identity weighting matrix with $90 \%, 95 \%$, and $99 \%$ critical values given by $0.0109,0.0165$, and 0.0273 respectively. The data employed in the estimation are annual and cover the period 1947:2003. 
Table 4: Tests of the LRR Model on the 2-Asset System

\begin{tabular}{|c|c|c|c|c|}
\hline \multirow[b]{3}{*}{ Estimated } & \multicolumn{4}{|c|}{ Panel A: identity weighting matrix } \\
\hline & $c_{1}$ & $c_{2}$ & $c_{3}$ & $c_{4}$ \\
\hline & $\begin{array}{c}-0.236 \\
(0.448)\end{array}$ & $\begin{array}{c}-5.242 \\
(64.76)\end{array}$ & $\begin{array}{c}-2.098 \\
(28.68)\end{array}$ & $\begin{array}{c}-4.071 \\
(2.482)\end{array}$ \\
\hline Predicted & 0.124 & -10.00 & -43.62 & 1.467 \\
\hline Pricing Errors & & Mean & & Std.Dev. \\
\hline Market & & 0.0128 & & 1.090 \\
\hline Risk free rate & & 0.0008 & & 1.071 \\
\hline \multirow[t]{3}{*}{$J-s t a t$} & $\begin{array}{l}0.378 \\
(<0.01)\end{array}$ & & & \\
\hline & \multicolumn{4}{|c|}{ Panel B: optimal weighting matrix } \\
\hline & $c_{1}$ & $c_{2}$ & $c_{3}$ & $c_{4}$ \\
\hline Estimated & $\begin{array}{c}-0.009 \\
(0.588)\end{array}$ & $\begin{array}{c}-31.09 \\
(92.01)\end{array}$ & $\begin{array}{c}-22.34 \\
(17.75)\end{array}$ & $\begin{array}{c}-2.575 \\
(7.169)\end{array}$ \\
\hline Predicted & 0.124 & -10.00 & -43.62 & 1.467 \\
\hline Pricing Errors & & Mean & & Std.Dev. \\
\hline Market & & 0.0202 & & 0.6596 \\
\hline Risk free rate & & 0.0095 & & 0.6539 \\
\hline$J-s t a t$ & $\begin{array}{l}3.078 \\
(0.215)\end{array}$ & & & \\
\hline
\end{tabular}

$\overline{\bar{T}}$ The table reports GMM estimates of the Bansal and Yaron (2004) LRR Model. Panel A reports results for the identity weighting matrix while Panel B reports the same for the efficient weighting matrix. The pricing kernel is a function of the consumption growth, the difference in the log price-dividend ratio of the market and its lag, and the risk free rate and its lag. The asset menu consists of the market portfolio, and the risk free rate. The lagged price-dividend ratio of the market and the lagged risk free rate are used as instruments. The table presents the parameter estimates along with the associated standard errors in parentheses. Average pricing errors along with the standard deviation of the errors are presented for each asset. The bottom line in each Panel reports the J-statistic for the overidentifying restrictions along with the associated p-values in parentheses. The J-statistic has a non-standard aymptotic distribution for the identity weighting matrix with $90 \%, 95 \%$, and $99 \%$ critical values given by $0.0001,0.0002$, and 0.0003 respectively, and an asymptotic $\chi^{2}$-distribution with two degrees of freedom for the efficient weighting matrix. The data employed in the estimation are quarterly and cover the period 1947:2:2003:3. 
Table 5: Tests of the LRR Model on the 6-Asset System

\begin{tabular}{|c|c|c|c|c|}
\hline \multirow[b]{3}{*}{ Estimated } & \multicolumn{4}{|c|}{ Panel A: identity weighting matrix } \\
\hline & $c_{1}$ & $c_{2}$ & $c_{3}$ & $c_{4}$ \\
\hline & $\begin{array}{c}-0.474 \\
(1.346)\end{array}$ & $\begin{array}{l}7.712 \\
(42.80)\end{array}$ & $\begin{array}{c}-2.484 \\
(40.81)\end{array}$ & $\begin{array}{c}-6.705 \\
(9.523)\end{array}$ \\
\hline Pr edicted & -0.373 & -10.00 & -146.0 & -3.152 \\
\hline Pricing Errors & & Mean & & Std.Dev \\
\hline Small & & 0.031 & & 0.911 \\
\hline$L \arg e$ & & -0.015 & & 0.886 \\
\hline$G$ row $t h$ & & -0.034 & & 0.846 \\
\hline Value & & 0.014 & & 0.910 \\
\hline Market & & -0.011 & & 0.883 \\
\hline Risk free rate & & 0.012 & & 1.078 \\
\hline \multirow[t]{3}{*}{$J-s t a t$} & $\begin{array}{l}0.211 \\
(<0.01)\end{array}$ & & & \\
\hline & \multicolumn{4}{|c|}{ Panel B: optimal weighting matrix } \\
\hline & $c_{1}$ & $c_{2}$ & $c_{3}$ & $c_{4}$ \\
\hline Estimated & $\begin{array}{c}-0.498 \\
(0.434)\end{array}$ & $\begin{array}{l}11.51 \\
(18.99)\end{array}$ & $\begin{array}{c}-13.68 \\
(9.943)\end{array}$ & $\begin{array}{c}-3.304 \\
(1.350)\end{array}$ \\
\hline Pr edicted & -0.373 & -10.00 & -146.0 & -3.152 \\
\hline Pricing Errors & & Mean & & Std.Dev \\
\hline Small & & 0.056 & & 0.988 \\
\hline$L \arg e$ & & -0.020 & & 0.854 \\
\hline$G$ row $t h$ & & -0.022 & & 0.907 \\
\hline Value & & 0.015 & & 0.847 \\
\hline Market & & -0.014 & & 0.862 \\
\hline Risk free rate & & -0.034 & & 0.923 \\
\hline \multirow[t]{3}{*}{$J-\operatorname{stat}$} & $\begin{array}{c}7.11 \\
(0.029) \\
\end{array}$ & & & \\
\hline & \multicolumn{4}{|c|}{ "Panel C: Hansen-Jagannathan matrix } \\
\hline & $c_{1}$ & $c_{2}$ & $c_{3}$ & $c_{4}$ \\
\hline Estimates & $\begin{array}{c}-0.542 \\
(0.511)\end{array}$ & $\begin{array}{l}11.23 \\
(22.76)\end{array}$ & $\begin{array}{l}-14.28 \\
(11.64)\end{array}$ & $\begin{array}{c}-4.185 \\
(1.827)\end{array}$ \\
\hline Pr edicted & -0.373 & -10.00 & -146.0 & -3.152 \\
\hline Pricing Errors & & Mean & & Std.Dev. \\
\hline Small & & 0.048 & & 1.052 \\
\hline$L \arg e$ & & -0.018 & & 0.948 \\
\hline$G$ row $t h$ & & -0.023 & & 0.988 \\
\hline Value & & 0.010 & & 0.944 \\
\hline Market & & -0.013 & & 0.955 \\
\hline Risk free rate & & -0.016 & & 1.055 \\
\hline$J-\operatorname{stat}$ & $\begin{array}{l}5.191 \\
(>0.10)\end{array}$ & & & \\
\hline
\end{tabular}

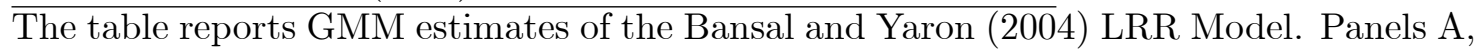


$\mathrm{B}$, and $\mathrm{C}$ report results for the identity, efficient, and Hansen-Jagannathan weighting matrices, respectively. The pricing kernel is a function of the consumption growth, the difference in the log price-dividend ratio of the market and its lag, and the risk free rate and its lag. The asset menu consists of the market portfolio, the risk free rate, the "Small", "Large", "Growth", and "Value" portfolios. The table presents the parameter estimates along with the associated standard errors in parentheses. Average pricing errors along with the standard deviation of the errors are presented for each asset. The bottom line in each Panel reports the J-statistic for the overidentifying restrictions along with the associated p-values in parentheses. The Jstatistic has a non-standard aymptotic distribution for the identity and Hansen-Jagannathan weighting matrices. The 90\%, 95\%, and 99\% critical values for the former are 0.042, 0.060, and 0.103 , respectively, while those for the latter are $13.73,18.23$, and 32.99 , respectively. For the efficient weighting matrix, the J-stat has an asymptotic $\chi^{2}$-distribution with two degrees of freedom. The data employed in the estimation are annual and cover the period 1930:2006. 
Table 6: Tests of the LRR Model with Alternative SDF

\begin{tabular}{|c|c|c|c|c|}
\hline \multirow[b]{2}{*}{ Estimated } & \multicolumn{4}{|c|}{ Panel A: identity weighting matrix } \\
\hline & $\begin{array}{c}c_{1} \\
-0.310 \\
(1.728)\end{array}$ & $\begin{array}{c}c_{2} \\
-5.173 \\
(151.7)\end{array}$ & $\begin{array}{c}c_{3} \\
-1.200 \\
(3.546)\end{array}$ & $\begin{array}{c}c_{4} \\
-2.407 \\
(10.87)\end{array}$ \\
\hline $\begin{array}{l}\text { Pricing Errors } \\
\text { Small } \\
L \text { arg } e \\
\text { Grow th } \\
\text { Value } \\
\text { Market } \\
\text { Risk free rate } \\
\text { J- stat }\end{array}$ & $\begin{array}{c}0.037 \\
(0.01-0.05)\end{array}$ & $\begin{array}{c}\text { Mean } \\
0.016 \\
-0.0003 \\
-0.0096 \\
-0.011 \\
-0.0001 \\
0.0045\end{array}$ & & $\begin{array}{c}\text { Std.Dev. } \\
0.974 \\
1.157 \\
1.137 \\
0.921 \\
1.141 \\
1.369\end{array}$ \\
\hline$J-s t a t$ & \multicolumn{4}{|c|}{ Panel B: optimal weighting matrix } \\
\hline Estimated & $\begin{array}{c}c_{1} \\
-0.145 \\
(0.778)\end{array}$ & $\begin{array}{c}c_{2} \\
-8.508 \\
(84.15)\end{array}$ & $\begin{array}{c}c_{3} \\
-1.180 \\
(2.033)\end{array}$ & $\begin{array}{c}c_{4} \\
-0.639 \\
(5.189)\end{array}$ \\
\hline $\begin{array}{l}\text { Pricing Errors } \\
\text { Small } \\
L \text { arg } e \\
\text { Grow th } \\
\text { Value } \\
\text { Market } \\
\text { Risk free rate } \\
\text { J- stat }\end{array}$ & $\begin{array}{l}6.704 \\
(0.035) \\
\end{array}$ & $\begin{array}{c}\text { Mean } \\
0.068 \\
0.022 \\
0.016 \\
0.038 \\
0.024 \\
-0.006\end{array}$ & & $\begin{array}{c}\text { Std.Dev. } \\
0.816 \\
0.837 \\
0.829 \\
0.745 \\
0.829 \\
0.956\end{array}$ \\
\hline Estimated & $\begin{array}{c}\text { Panel } C \text { : } \\
c_{1} \\
-0.208 \\
(1.043)\end{array}$ & $\begin{array}{c}\text { Hansen-J } \\
c_{2} \\
-7.202 \\
(98.98)\end{array}$ & $\begin{array}{c}\text { agannatho } \\
c_{3} \\
-1.098 \\
(2.191)\end{array}$ & $\begin{array}{c}\text { an matrix } \\
c_{4} \\
-2.114 \\
(6.288)\end{array}$ \\
\hline $\begin{array}{l}\text { Pricing Errors } \\
\text { Small } \\
\text { L arg } e \\
\text { Grow th } \\
\text { Value } \\
\text { Market } \\
\text { Risk free rate } \\
\text { J- stat }\end{array}$ & $\begin{array}{c}4.267 \\
(0.05-0.10)\end{array}$ & $\begin{array}{c}\text { Mean } \\
0.030 \\
0.002 \\
-0.007 \\
0.004 \\
0.003 \\
-0.005\end{array}$ & & $\begin{array}{c}\text { Std.Dev. } \\
0.829 \\
0.946 \\
0.930 \\
0.778 \\
0.932 \\
1.114\end{array}$ \\
\hline
\end{tabular}

The table reports GMM estimates of the Bansal and Yaron (2004) LRR Model. Panels 
A, B, and C report results for the identity, efficient, and Hansen-Jagannathan weighting matrices, respectively. The pricing kernel is a function of the consumption growth, the difference in the log price-dividend ratio of the market and its lag, and the difference in the log price-dividend ratios of the "Value" and "Growth" portfolios and its lag. The asset menu consists of the market portfolio, the risk free rate, the "Small", "Large", "Growth", and "Value" portfolios. The table presents the parameter estimates along with the associated standard errors in parentheses. Average pricing errors along with the standard deviation of the errors are presented for each asset. The bottom line in each Panel reports the J-statistic for the overidentifying restrictions along with the associated p-values in parentheses. The Jstatistic has a non-standard aymptotic distribution for the identity and Hansen-Jagannathan weighting matrices. The $90 \%, 95 \%$, and $99 \%$ critical values for the former are $0.017,0.028$, and 0.049 , respectively, while those for the latter are $3.220,4.466$, and 7.349 , respectively. For the efficient weighting matrix, the J-stat has an asymptotic $\chi^{2}$-distribution with two degrees of freedom. The data employed in the estimation are annual and cover the period 1930:2006. 
Table 7: Tests of the LRR Model on the 6-Asset System

\begin{tabular}{|c|c|c|c|c|}
\hline \multirow[b]{3}{*}{ Estimated } & \multicolumn{4}{|c|}{ Panel A: identity weighting matrix } \\
\hline & $c_{1}$ & $c_{2}$ & $c_{3}$ & $c_{4}$ \\
\hline & $\begin{array}{c}-0.293 \\
(0.248)\end{array}$ & $\begin{array}{c}-67.36 \\
(36.51)\end{array}$ & $\begin{array}{l}1.141 \\
(52.02)\end{array}$ & $\begin{array}{c}-1.643 \\
(5.688)\end{array}$ \\
\hline Predicted & -0.988 & -10.00 & -26.17 & -6.438 \\
\hline Pricing Errors & & Mean & & Std.Dev. \\
\hline Small & & $-2.6 \times 10^{-3}$ & & 3.181 \\
\hline$L \arg e$ & & $7.7 \times 10^{-3}$ & & 3.455 \\
\hline$G$ row $t h$ & & $-7.3 \times 10^{-3}$ & & 3.336 \\
\hline Value & & $4.8 \times 10^{-3}$ & & 3.284 \\
\hline Market & & $6.4 \times 10^{-3}$ & & 3.376 \\
\hline Risk free rate & & $-2.7 \times 10^{-3}$ & & 3.388 \\
\hline \multirow[t]{3}{*}{$J-s t a t$} & $\begin{array}{l}0.009 \\
(>0.10)\end{array}$ & & & \\
\hline & \multicolumn{4}{|c|}{ Panel B: Hansen-Jagannathan matrix } \\
\hline & $c_{1}$ & $c_{2}$ & $c_{3}$ & $c_{4}$ \\
\hline Estimated & $\begin{array}{c}-1.501 \\
(1.811)\end{array}$ & $\begin{array}{c}-45.78 \\
(47.55)\end{array}$ & $\begin{array}{l}32.67 \\
(16.53)\end{array}$ & $\begin{array}{c}-10.30 \\
(11.92)\end{array}$ \\
\hline Predicted & -0.988 & -10.00 & -26.17 & -6.438 \\
\hline Pricing Errors & & Mean & & Std.Dev. \\
\hline Small & & 0.034 & & 3.244 \\
\hline$L \arg e$ & & 0.039 & & 3.274 \\
\hline$G$ row $t h$ & & 0.039 & & 3.337 \\
\hline Value & & 0.050 & & 3.240 \\
\hline Market & & 0.036 & & 3.259 \\
\hline Risk free rate & & 0.028 & & 3.097 \\
\hline$J-s t a t$ & $\begin{array}{l}1.541 \\
(>0.10)\end{array}$ & & & \\
\hline
\end{tabular}

$\overline{\bar{T} \text { The table reports GMM estimates of the Bansal and Yaron (2004) LRR }}$ Model. Panels A and B report results for the identity and Hansen-Jagannathan weighting matrices, respectively. The pricing kernel is a function of the consumption growth, the log price-dividend ratio of the market and its lag, and the risk free rate and its lag. The asset menu consists of the market portfolio, the risk free rate, the "Small", "Large", "Growth", and "Value" portfolios. The table presents the parameter estimates along with the associated standard errors in parentheses. Average pricing errors along with the standard deviation of the errors are presented for each asset. The bottom line in each Panel reports the J-statistic for the overidentifying restrictions along with the associated p-values in parentheses. The J-statistic has a non-standard aymptotic distribution for the identity and Hansen-Jagannathan weighting matrices. The 90\%, 95\%, and 99\% critical values for the former are 0.023, 0.033, and 0.057 , respectively, while those for the latter are 5.854, 7.922, and 13.40, respectively. The data employed in the estimation are annual and cover the period 1947:2003. 
Table 8: Tests of the LRR Model with Alternative SDF

\begin{tabular}{|c|c|c|c|c|}
\hline \multirow[b]{3}{*}{ Estimated } & \multicolumn{4}{|c|}{ Panel A: identity weighting matrix } \\
\hline & $c_{1}$ & $c_{2}$ & $c_{3}$ & $c_{4}$ \\
\hline & $\begin{array}{c}-0.855 \\
(1.004)\end{array}$ & $\begin{array}{c}-106.0 \\
(49.27)\end{array}$ & $\begin{array}{l}2.198 \\
(2.982)\end{array}$ & $\begin{array}{l}0.705 \\
(3.377)\end{array}$ \\
\hline Pricing Errors & \multicolumn{3}{|c|}{ Mean } & Std.Dev. \\
\hline Small & \multicolumn{3}{|c|}{$-8.1 \times 10^{-4}$} & 3.560 \\
\hline$L \arg e$ & \multicolumn{3}{|c|}{$1.7 \times 10^{-3}$} & 3.799 \\
\hline$G$ row $t h$ & \multicolumn{3}{|c|}{$1.2 \times 10^{-3}$} & 3.710 \\
\hline Value & \multicolumn{3}{|c|}{$1.7 \times 10^{-3}$} & 3.642 \\
\hline Market & \multicolumn{3}{|c|}{$-3.7 \times 10^{-3}$} & 3.726 \\
\hline Risk free rate & \multicolumn{3}{|c|}{$2.0 \times 10^{-6}$} & 3.814 \\
\hline \multirow[t]{3}{*}{$J-$ stat } & \multicolumn{4}{|c|}{$\begin{array}{c}0.0012 \\
(>0.10)\end{array}$} \\
\hline & \multicolumn{4}{|c|}{ Panel B: Hansen-Jagannathan matrix } \\
\hline & $c_{1}$ & $c_{2}$ & $c_{3}$ & $c_{4}$ \\
\hline Estimated & $\begin{array}{c}-0.873 \\
(2.531)\end{array}$ & $\begin{array}{l}0.288 \\
(33.68)\end{array}$ & $\begin{array}{l}-5.41 \\
(9.270)\end{array}$ & $\begin{array}{c}-3.941 \\
(3.614)\end{array}$ \\
\hline Pricing Errors & & Mean & & Std.Dev. \\
\hline Small & & 0.083 & & 1.633 \\
\hline$L \arg e$ & & 0.064 & & 1.608 \\
\hline$G$ row $t h$ & & 0.046 & & 1.551 \\
\hline Value & & 0.101 & & 1.722 \\
\hline Market & & 0.065 & & 1.611 \\
\hline Risk free rate & & 0.040 & & 1.614 \\
\hline$J-s t a t$ & $\begin{array}{c}6.429 \\
(0.05-0.10) \\
\end{array}$ & & & \\
\hline
\end{tabular}

$\overline{\bar{T} \text { The table reports GMM estimates of the Bansal and Yaron (2004) LR}}$ R Model. Panels A and B report results for the identity and Hansen-Jagannathan weighting matrices, respectively. The pricing kernel is a function of the consumption growth, the log price-dividend ratio of the market and its lag, and the difference in the log price-dividend ratio of value and growth portfolios and its lag. The asset menu consists of the market portfolio, the risk free rate, the "Small", "Large", "Growth", and "Value" portfolios. The table presents the parameter estimates along with the associated standard errors in parentheses. Average pricing errors along with the standard deviation of the errors are presented for each asset. The bottom line in each Panel reports the J-statistic for the overidentifying restrictions along with the associated p-values in parentheses. The J-statistic has a non-standard aymptotic distribution for the identity and Hansen-Jagannathan weighting matrices. The $90 \%, 95 \%$, and $99 \%$ critical values for the former are $0.0034,0.0051$, and 0.0094 , respectively, while those for the latter are 5.348, 7.197, and 11.80, respectively. The data employed in the estimation are annual and cover the period 1947:2003. 
Table 9: Tests of the LRR Model on the 6-Asset System

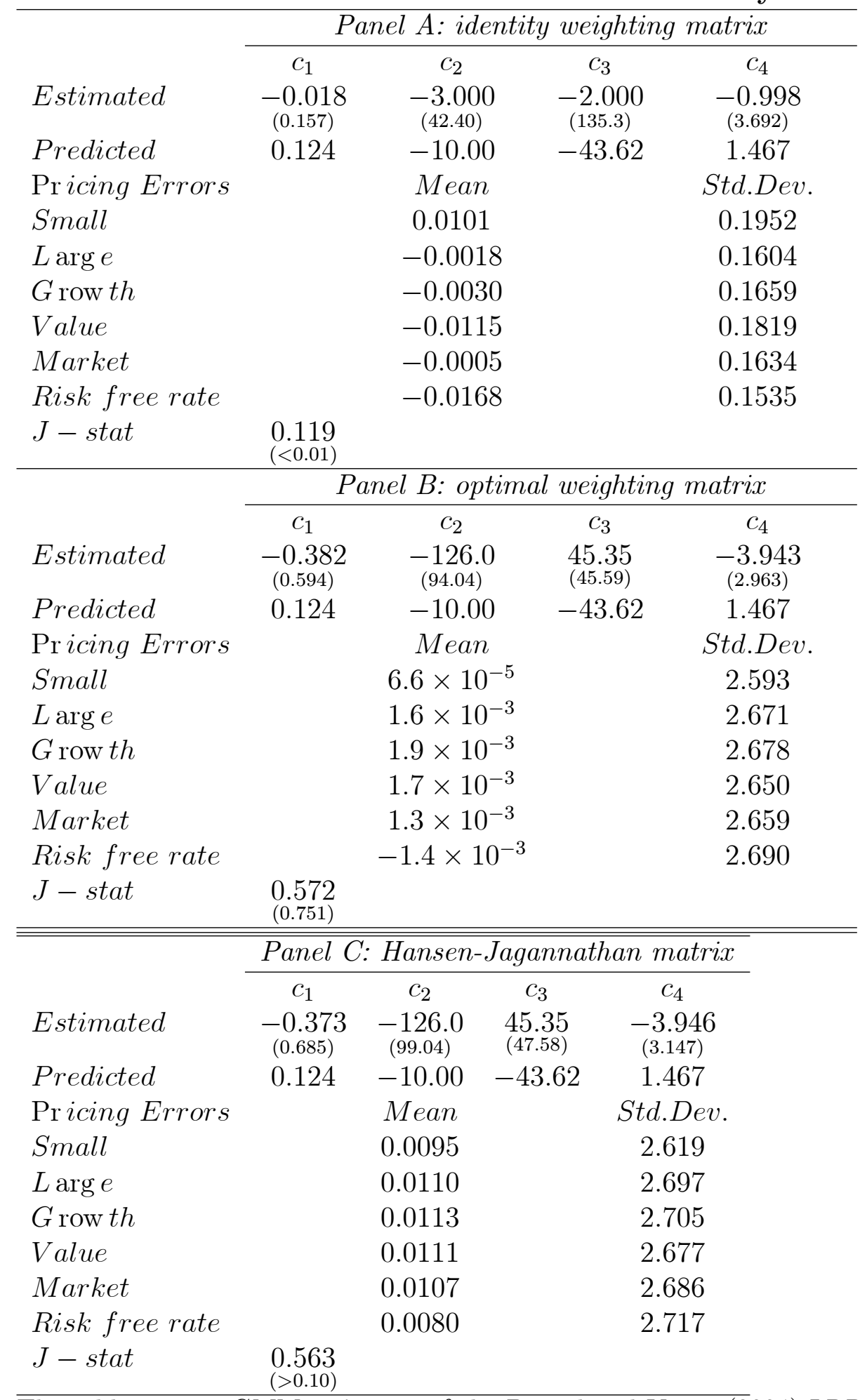

The table reports GMM estimates of the Bansal and Yaron (2004) LRR Model. Panels 
A, B, and C report results for the identity, efficient, and Hansen-Jagannathan weighting matrices, respectively. The pricing kernel is a function of the consumption growth, the log price-dividend ratio of the market and its lag, and the risk free rate and its lag. The asset menu consists of the market portfolio, the risk free rate, the "Small", "Large", "Growth", and "Value" portfolios. The table presents the parameter estimates along with the associated standard errors in parentheses. Average pricing errors along with the standard deviation of the errors are presented for each asset. The bottom line in each Panel reports the J-statistic for the overidentifying restrictions along with the associated p-values in parentheses. The Jstatistic has a non-standard aymptotic distribution for the identity and Hansen-Jagannathan weighting matrices. The $90 \%, 95 \%$, and $99 \%$ critical values for the former are $0.0026,0.0035$, and 0.0049 , respectively, while those for the latter are 4.477, 5.789, and 9.040, respectively. For the efficient weighting matrix, the J-stat has an asymptotic $\chi^{2}$-distribution with two degrees of freedom. The data employed in the estimation are quarterly and cover the period 1947:2:2003:3. 
Table 10: Tests of the LRR Model with Alternative SDF

\begin{tabular}{|c|c|c|c|c|}
\hline \multirow[b]{2}{*}{ Estimated } & \multicolumn{4}{|c|}{ Panel A: identity weighting matrix } \\
\hline & $\begin{array}{c}c_{1} \\
-0.307 \\
(0.530)\end{array}$ & $\begin{array}{c}c_{2} \\
-3.027 \\
(82.10)\end{array}$ & $\begin{array}{c}c_{3} \\
-3.020 \\
(1.423)\end{array}$ & $\begin{array}{c}c_{4} \\
-0.849 \\
(2.414)\end{array}$ \\
\hline $\begin{array}{l}\text { Pricing Errors } \\
\text { Small } \\
L \text { arg } e \\
\text { Grow th } \\
\text { Value } \\
\text { Market } \\
\text { Risk free rate } \\
\text { J-stat }\end{array}$ & $\begin{array}{l}0.035 \\
(<0.01)\end{array}$ & $\begin{array}{c}\text { Mean } \\
0.0018 \\
-0.0035 \\
-0.0059 \\
0.0096 \\
-0.0031 \\
0.0008\end{array}$ & & $\begin{array}{c}\text { Std.Dev. } \\
1.088 \\
1.129 \\
1.116 \\
1.142 \\
1.125 \\
1.284\end{array}$ \\
\hline$J-s t a t$ & \multicolumn{4}{|c|}{ Panel B: optimal weighting matrix } \\
\hline Estimated & $\begin{array}{c}c_{1} \\
-0.319 \\
(2.870)\end{array}$ & $\begin{array}{c}c_{2} \\
-133.5 \\
(396.8)\end{array}$ & $\begin{array}{c}c_{3} \\
1.129 \\
(2.132)\end{array}$ & $\begin{array}{c}c_{4} \\
-3.128 \\
(8.439)\end{array}$ \\
\hline $\begin{array}{l}\text { Pricing Errors } \\
\text { Small } \\
\text { L arge } \\
\text { Grow th } \\
\text { Value } \\
\text { Market } \\
\text { Risk free rate } \\
\text { J-stat }\end{array}$ & $\begin{array}{l}0.988 \\
(0.610) \\
\end{array}$ & $\begin{array}{c}\text { Mean } \\
-0.019 \\
-0.025 \\
-0.025 \\
-0.021 \\
-0.024 \\
-0.036\end{array}$ & & $\begin{array}{c}\text { Std.Dev. } \\
2.077 \\
2.035 \\
2.045 \\
2.070 \\
2.041 \\
1.957\end{array}$ \\
\hline Estimated & $\begin{array}{c}\text { Panel } \\
c_{1} \\
-0.452 \\
(1.576)\end{array}$ & $\begin{array}{c}\text { Hansen- } \\
c_{2} \\
-152.7 \\
(181.1)\end{array}$ & $\begin{array}{c}\text { Jagannat } \\
c_{3} \\
-0.275 \\
(2.221)\end{array}$ & $\begin{array}{c}c_{4} \\
-3.823 \\
(3.528)\end{array}$ \\
\hline $\begin{array}{l}\text { Pricing Errors } \\
\text { Small } \\
\text { Large } \\
\text { Grow th } \\
\text { Value } \\
\text { Market } \\
\text { Risk free rate } \\
\text { J-stat }\end{array}$ & $\begin{array}{l}3.140 \\
(>0.10)\end{array}$ & $\begin{array}{c}\text { Mean } \\
0.0199 \\
0.0139 \\
0.0123 \\
0.0220 \\
0.0150 \\
0.0121\end{array}$ & & $\begin{array}{c}\text { Std.Dev. } \\
3.044 \\
3.058 \\
3.059 \\
3.113 \\
3.054 \\
3.077\end{array}$ \\
\hline
\end{tabular}

The table reports GMM estimates of the Bansal and Yaron (2004) LRR Model. Panels 
A, B, and C report results for the identity, efficient, and Hansen-Jagannathan weighting matrices, respectively. The pricing kernel is a function of the consumption growth, the log price-dividend ratio of the market and its lag, and the difference in the log price-dividend ratio of value and growth portfolios and its lag. The asset menu consists of the market portfolio, the risk free rate, the "Small", "Large", "Growth", and "Value" portfolios. The table presents the parameter estimates along with the associated standard errors in parentheses. Average pricing errors along with the standard deviation of the errors are presented for each asset. The bottom line in each Panel reports the J-statistic for the overidentifying restrictions along with the associated p-values in parentheses. The J-statistic has a non-standard aymptotic distribution for the identity and Hansen-Jagannathan weighting matrices. The 90\%, 95\%, and $99 \%$ critical values for the former are $0.0025,0.0034$, and 0.0055 , respectively, while those for the latter are 5.943, 7.579, and 12.22, respectively. For the efficient weighting matrix, the J-stat has an asymptotic $\chi^{2}$-distribution with two degrees of freedom. The data employed in the estimation are annual and cover the period 1947:2:2003:3. 
Table 11: Estimates of Time-Series Parameters

\begin{tabular}{lcccccccc}
$\mu$ & $\mu_{d}$ & $\phi$ & $\varphi_{d}$ & $\rho$ & $\varphi_{e}$ & $\sigma$ & $v$ & $\sigma_{w}$ \\
\hline 0.015 & 0.014 & 2.188 & 5.871 & 0.990 & 0.207 & 0.016 & 0.994 & $3.2 \times 10^{-5}$ \\
$(0.003)$ & $(0.013)$ & $(0.546)$ & $(3.031)$ & $(0.448)$ & $(4.744)$ & $(0.007)$ & $(3.046)$ & $(0.009)$
\end{tabular}

The table reports GMM estimates of parameters, along with the standard errors in parentheses, of the time-series processes in the Bansal and Yaron (2004) LRR Model, over the sample period 1930-2006. 
Table 12: Simulation Results for 2-Asset System

\begin{tabular}{lcccc}
\hline & \multicolumn{5}{c}{ Panel A: identity weighting matrix } \\
\cline { 2 - 5 } Estimated & $c_{1}$ & $c_{2}$ & $c_{3}$ & $c_{4}$ \\
& -0.199 & -5.063 & -2.260 & -8.178 \\
& $(0.391)$ & $(3.066)$ & $(0.198)$ & $(5.468)$ \\
$J-$ stat & 0.018 & 0.123 & 0.738 & \\
& $(0.90)$ & $(0.95)$ & $(0.99)$ & \\
\cline { 2 - 5 } Panel B: optimal weighting & matrix \\
\cline { 2 - 5 } Estimated & $c_{1}$ & $c_{2}$ & $c_{3}$ & $c_{4}$ \\
& -0.111 & -17.94 & -2.292 & -8.918 \\
& $(0.379)$ & $(21.68)$ & $(0.235)$ & $(5.702)$ \\
J-stat & 0.032 & 0.159 & 1.760 & \\
& $(0.90)$ & $(0.95)$ & $(0.99)$ & \\
\hline \hline
\end{tabular}

The table reports simulation results of the Bansal and Yaron (2004) LRR Model. 225 Monte-Carlo simulations, each of size 76, are performed for the choice of parameters in Section 5. Panel A reports results for the identity weighting matrix while Panel B reports the same for the efficient weighting matrix. The pricing kernel is a function of the consumption growth, the difference in the log price-dividend ratio of the market and its lag, and the risk free rate and its lag. The asset menu consists of the market portfolio, and the risk free rate. The lagged price-dividend ratio of the market and the lagged risk free rate are used as instruments. 
Table 13: Simulation Results for 6-Asset System

\begin{tabular}{|c|c|c|c|c|}
\hline \multirow[b]{3}{*}{ Estimated } & \multicolumn{4}{|c|}{ Panel A: identity weighting matrix } \\
\hline & $c_{1}$ & $c_{2}$ & $c_{3}$ & $c_{4}$ \\
\hline & $\begin{array}{c}-0.091 \\
(0.093)\end{array}$ & $\begin{array}{c}-4.604 \\
(3.165)\end{array}$ & $\begin{array}{c}-2.198 \\
(0.089)\end{array}$ & $\begin{array}{c}-6.426 \\
(2.514)\end{array}$ \\
\hline \multirow[t]{2}{*}{$J-s t a t$} & $\begin{array}{c}0.183 \\
(0.90)\end{array}$ & $\begin{array}{c}0.210 \\
(0.95)\end{array}$ & $\begin{array}{c}0.285 \\
(0.99)\end{array}$ & \\
\hline & \multicolumn{4}{|c|}{ Panel B: optimal weighting matrix } \\
\hline Estimated & $\begin{array}{c}c_{1} \\
-0.281 \\
(0.572)\end{array}$ & $\begin{array}{c}c_{2} \\
-1.663 \\
(29.38)\end{array}$ & $\begin{array}{c}c_{3} \\
-2.268 \\
(0.432)\end{array}$ & $\begin{array}{c}c_{4} \\
-7.591 \\
(3.583)\end{array}$ \\
\hline \multirow[t]{2}{*}{$J-s t a t$} & $\begin{array}{l}7.15 \\
(0.90) \\
\end{array}$ & $\begin{array}{l}8.45 \\
(0.95) \\
\end{array}$ & $\begin{array}{c}12.91 \\
(0.99) \\
\end{array}$ & \\
\hline & \multicolumn{4}{|c|}{ Panel C: Hansen-Jagannathan matrix } \\
\hline Estimated & $\begin{array}{c}c_{1} \\
-0.274 \\
(0.541)\end{array}$ & $\begin{array}{c}c_{2} \\
-1.026 \\
(28.43)\end{array}$ & $\begin{array}{c}c_{3} \\
-2.254 \\
(0.458)\end{array}$ & $\begin{array}{c}c_{4} \\
-7.390 \\
(3.305)\end{array}$ \\
\hline$J-s t a t$ & $\begin{array}{l}4.50 \\
(0.90) \\
\end{array}$ & $\begin{array}{c}12.25 \\
(0.95)\end{array}$ & $\begin{array}{c}17.02 \\
(0.99)\end{array}$ & \\
\hline
\end{tabular}

The table reports simulation results of the Bansal and Yaron (2004) LRR Model. 95 Monte-Carlo simulations, each of size 76, are performed for the choice of parameters in Section 5. Panels A, B, and C report results for the identity, efficient, and Hansen-Jagannathan weighting matrices, respectively. The pricing kernel is a function of the consumption growth, the difference in the log price-dividend ratio of the market and its lag, and the risk free rate and its lag. The asset menu consists of the market portfolio, the risk free rate, the "Small", "Large", "Growth", and "Value" portfolios. 
Table 14: Estimates of Time-Series Parameters

\begin{tabular}{lcccccccc}
$\mu$ & $\mu_{d}$ & $\phi$ & $\varphi_{d}$ & $\rho$ & $\varphi_{e}$ & $\sigma$ & $v$ & $\sigma_{w}$ \\
\hline 0.013 & 0.023 & 1.930 & 6.170 & 0.967 & 0.227 & 0.010 & 0.994 & $3.4 \times 10^{-6}$ \\
$(0.002)$ & $(0.010)$ & $(1.856)$ & $(3.111)$ & $(1.255)$ & $(4.457)$ & $(0.005)$ & $(87.64)$ & $(0.022)$
\end{tabular}

The table reports GMM estimates of parameters, along with the standard errors in parentheses, of the time-series processes in the Bansal and Yaron (2004) LRR Model, over the sample period 1947-2003. 
Table 15: Estimates of Time-Series Parameters

\begin{tabular}{ccccccccc}
$\mu$ & $\mu_{d}$ & $\phi$ & $\varphi_{d}$ & $\rho$ & $\varphi_{e}$ & $\sigma$ & $v$ & $\sigma_{w}$ \\
\hline 0.004 & 0.006 & 1.917 & 6.174 & 0.621 & 0.113 & 0.023 & 0.988 & $8.9 \times 10^{-5}$ \\
$(0.0006)$ & $(0.006)$ & $(91.57)$ & $(3.888)$ & $(29.31)$ & $(6.063)$ & $(0.012)$ & $(360.8)$ & $(1.338)$
\end{tabular}

The table reports GMM estimates of parameters, along with the standard errors in parentheses, of the time-series processes in the Bansal and Yaron (2004) LRR Model, over the sample period 1947:2-2003:3. 
Table 16: Tests of the Extended LRR Model on the 2-Asset System

\begin{tabular}{|c|c|c|c|c|c|}
\hline \multirow[b]{3}{*}{ Estimated } & \multicolumn{5}{|c|}{ Panel A: identity weighting matrix } \\
\hline & $c_{1}$ & $c_{2}$ & $c_{3}$ & $c_{4}$ & $c_{5}$ \\
\hline & $\begin{array}{c}-0.207 \\
(0.415)\end{array}$ & $\begin{array}{l}4.941 \\
(19.85)\end{array}$ & $\begin{array}{c}-2.144 \\
(14.35)\end{array}$ & $\begin{array}{c}-3.938 \\
(1.777)\end{array}$ & $\begin{array}{c}-3.288 \\
(3.800)\end{array}$ \\
\hline Pr edicted & 0.124 & -10 & -30.48 & -4.828 & -1.035 \\
\hline Pricing Errors & & Mean & & Std.Dev. & \\
\hline Market & & -0.0011 & & 0.478 & \\
\hline Risk free rate & & -0.0060 & & 0.646 & \\
\hline \multirow[t]{3}{*}{$J-$ stat } & $\begin{array}{c}0.0031 \\
(0.01-0.05)\end{array}$ & & & & \\
\hline & \multicolumn{5}{|c|}{ Panel B: optimal weighting matrix } \\
\hline & $c_{1}$ & $c_{2}$ & $c_{3}$ & $c_{4}$ & $c_{5}$ \\
\hline Estimated & $\begin{array}{c}-0.736 \\
(0.549)\end{array}$ & $\begin{array}{l}13.66 \\
(15.71)\end{array}$ & $\begin{array}{c}-14.79 \\
(9.816)\end{array}$ & $\begin{array}{c}-5.439 \\
(3.049)\end{array}$ & $\begin{array}{l}2.143 \\
(8.114)\end{array}$ \\
\hline Pr edicted & 0.124 & -10 & -30.48 & -4.828 & -1.035 \\
\hline Pricing Errors & & Mean & & Std.Dev. & \\
\hline Market & & 0.0052 & & 1.181 & \\
\hline Risk free rate & & 0.0052 & & 1.251 & \\
\hline$J-s t a t$ & $\begin{array}{l}0.290 \\
(0.590)\end{array}$ & & & & \\
\hline
\end{tabular}

$\overline{\text { The table reports GMM estimates of the Extended version of the Long Run Risk Model. }}$ Panels A and B report results for the identity and efficient weighting matrices respectively The pricing kernel is a function of the consumption growth, the difference in the log risk free rate and its lag, the log price-dividend ratio of the market and its lag, the difference in the demeaned log dividend-consumption ratio and its lag. The asset menu consists of the market portfolio and the risk free rate. The lagged price-dividend ratio of the market and the lagged risk free rate are used as instruments. The table presents the parameter estimates along with the standard errors in parentheses. Average pricing errors along with the standard deviation of the errors are presented for each asset. The bottom line in each Panel reports the J-statistic for overidentifying restrictions along with the p-values in parentheses. The J-statistic has a non-standard aymptotic distribution for the identity weighting matrix with $90 \%, 95 \%$, and $99 \%$ critical values given by $0.0014,0.0020$, and 0.0033 respectively, and an asymptotic $\chi^{2}$-distribution with one degree of freedom for the efficient weighting matrix. The data employed in the estimation are annual and cover the period 1930:2006. 


\section{Table 17: Estimates of Time-Series Parameters}

\begin{tabular}{lccccccc}
$\mu$ & $\mu_{d c}$ & $\rho_{x}$ & $\varphi_{e}$ & $\sigma$ & $\lambda_{s x}$ & $\rho_{s}$ & $\psi_{s}$ \\
\hline 0.015 & 7.700 & 0.926 & 0.212 & 0.023 & 1.442 & 1.051 & 4.043 \\
$(0.003)$ & $(0.030)$ & $(0.741)$ & $(1.143)$ & $(0.004)$ & $(4.241)$ & $(0.572)$ & $(1.757)$
\end{tabular}

The table reports GMM estimates of parameters, along with the standard errors in parentheses, of the time-series processes in the Bansal, Gallant, and Tauchen (2007) LRR Model, over the sample period 1930-2006. 


\section{Table 18: Tests of the Extended LRR Model on the 2-Asset System}

\begin{tabular}{lccccc}
\hline & \multicolumn{5}{c}{ Panel A: identity weighting matrix } \\
\cline { 2 - 6 } Estimated & $c_{1}$ & $c_{2}$ & $c_{3}$ & $c_{4}$ & $c_{5}$ \\
& -0.234 & 2.919 & -0.479 & -5.163 & 0.663 \\
Predicted & $(0.742)$ & $(31.40)$ & $(26.87)$ & $(4.520)$ & $(10.70)$ \\
Pricing Errors & 0.116 & -10.00 & 3.331 & -3.089 & -0.662 \\
Market & & Mean & & Std.Dev. & \\
Risk free rate & & -0.0028 & & 0.6705 & \\
$J-$ stat & & -0.0087 & & 0.7921 & \\
& 0.0109 & & & & \\
\hline
\end{tabular}

$\overline{\text { The table reports GMM estimates of the Extended version of the Long Run Risk Model. }}$. Panels A reports results for the identity weighting matrix. The pricing kernel is a function of the consumption growth, the log risk free rate and its lag, the log price-dividend ratio of the market and its lag, and the difference in the demeaned log dividend-consumption ratio and its lag. The asset menu consists of the market portfolio and the risk free rate. The lagged pricedividend ratio of the market and the lagged risk free rate are used as instruments. The table presents the parameter estimates along with the standard errors in parentheses. Average pricing errors along with the standard deviation of the errors are presented for each asset. The bottom line in each Panel reports the J-statistic for overidentifying restrictions along with the p-values in parentheses. The J-statistic has a non-standard aymptotic distribution for the identity weighting matrix with $90 \%, 95 \%$, and $99 \%$ critical values given by 0.0009 , 0.0013 , and 0.0026 respectively. The data employed in the estimation are annual and cover the period 1947-2003. 


\section{Table 19: Estimates of Time-Series Parameters}

\begin{tabular}{lccccccc}
$\mu$ & $\mu_{d c}$ & $\rho_{x}$ & $\varphi_{e}$ & $\sigma$ & $\lambda_{s x}$ & $\rho_{s}$ & $\psi_{s}$ \\
\hline 0.013 & 7.694 & 0.824 & 0.279 & 0.015 & 3.575 & 1.025 & 3.259 \\
$(0.002)$ & $(0.023)$ & $(0.807)$ & $(0.753)$ & $(0.002)$ & $(16.00)$ & $(0.933)$ & $(3.223)$
\end{tabular}

The table reports GMM estimates of parameters, along with the standard errors in parentheses, of the time-series processes in the Bansal, Gallant, and Tauchen (2007) LRR Model, over the sample period 1947-2003. 
Table 20: Tests of the Extended LRR Model on the 2-Asset System

\begin{tabular}{|c|c|c|c|c|c|}
\hline \multirow[b]{3}{*}{ Estimated } & \multicolumn{5}{|c|}{ Panel A: identity weighting matrix } \\
\hline & $c_{1}$ & $c_{2}$ & $c_{3}$ & $c_{4}$ & $c_{5}$ \\
\hline & $\begin{array}{c}-0.424 \\
(0.523)\end{array}$ & $\begin{array}{l}4.609 \\
(62.00)\end{array}$ & $\begin{array}{c}-2.062 \\
(56.38)\end{array}$ & $\begin{array}{c}-4.485 \\
(5.884)\end{array}$ & $\begin{array}{c}-3.587 \\
(4.202)\end{array}$ \\
\hline Predicted & -12.46 & -10.00 & -32.49 & -22.92 & -22.69 \\
\hline Pricing Errors & & Mean & & Std.Dev. & \\
\hline Market & & 0.0121 & & 1.107 & \\
\hline Risk free rate & & 0.0035 & & 1.087 & \\
\hline \multirow[t]{3}{*}{$J-s t a t$} & $\begin{array}{l}0.207 \\
(<0.01)\end{array}$ & & & & \\
\hline & \multicolumn{5}{|c|}{ Panel B: optimal weighting matrix } \\
\hline & $c_{1}$ & $c_{2}$ & $c_{3}$ & $c_{4}$ & $c_{5}$ \\
\hline Estimated & $\begin{array}{c}-0.078 \\
(2.213)\end{array}$ & $\begin{array}{c}-27.08 \\
(311.6)\end{array}$ & $\begin{array}{c}-20.68 \\
(42.99)\end{array}$ & $\begin{array}{c}-1.994 \\
(26.09)\end{array}$ & $\begin{array}{c}-2.549 \\
(2.598)\end{array}$ \\
\hline Predicted & -12.46 & -10.00 & -32.49 & -22.92 & -22.69 \\
\hline Pricing Errors & & Mean & & Std.Dev. & \\
\hline Market & & 0.0144 & & 0.658 & \\
\hline Risk free rate & & 0.0069 & & 0.658 & \\
\hline$J-s t a t$ & $\begin{array}{l}1.948 \\
(0.163)\end{array}$ & & & & \\
\hline
\end{tabular}

$\overline{\text { The table reports GMM estimates of the Extended version of the Long Run Risk Model. }}$ Panels A and B report results for the identity and efficient weighting matrices respectively The pricing kernel is a function of the consumption growth, the log risk free rate and its lag, the log price-dividend ratio of the market and its lag, and the difference in the demeaned $\log$ dividend-consumption ratio and its lag. The asset menu consists of the market portfolio and the risk free rate. The lagged price-dividend ratio of the market and the lagged risk free rate are used as instruments. The table presents the parameter estimates along with the standard errors in parentheses. Average pricing errors along with the standard deviation of the errors are presented for each asset. The bottom line in each Panel reports the J-statistic for overidentifying restrictions along with the $\mathrm{p}$-values in parentheses. The J-statistic has a non-standard aymptotic distribution for the identity weighting matrix with 90\%, 95\%, and $99 \%$ critical values given by $1.4 \times 10^{-5}, 2.1 \times 10^{-5}$, and $3.7 \times 10^{-5}$ respectively, and an asymptotic $\chi^{2}$-distribution with one degree of freedom for the efficient weighting matrix. The data employed in the estimation are quarterly and cover the period 1947:2:2003:3. 
Table 21: Estimates of Time-Series Parameters

\begin{tabular}{cccccccc}
$\mu$ & $\mu_{d c}$ & $\rho_{x}$ & $\varphi_{e}$ & $\sigma$ & $\lambda_{s x}$ & $\rho_{s}$ & $\psi_{s}$ \\
\hline 0.004 & -5.868 & 0.964 & 0.226 & 0.005 & 1.849 & 0.551 & 5.732 \\
$(0.0006)$ & $(0.014)$ & $(0.528)$ & $(1.810)$ & $(0.002)$ & $(82.89)$ & $(3.133)$ & $(10.34)$
\end{tabular}

The table reports GMM estimates of parameters, along with the standard errors in parentheses, of the time-series processes in the Bansal, Gallant, and Tauchen (2007) LRR Model, over the sample period 1947:2-2003:3. 
Table 22: Tests of the Extended LRR Model on the 6-Asset System

\begin{tabular}{|c|c|c|c|c|c|c|}
\hline \multirow[b]{3}{*}{ Estimated } & \multicolumn{6}{|c|}{ Panel A: identity weighting matrix } \\
\hline & $c_{1}$ & $c_{2}$ & $c_{3}$ & $c_{4}$ & & $c_{5}$ \\
\hline & $\begin{array}{c}-4.440 \\
(5.325)\end{array}$ & $\begin{array}{c}-4.039 \\
(24.72)\end{array}$ & $\begin{array}{l}6.356 \\
(39.50)\end{array}$ & $\begin{array}{l}-21.22 \\
(22.16)\end{array}$ & & $\begin{array}{l}15.78 \\
(8.033)\end{array}$ \\
\hline Pr edicted & 0.124 & -10 & -30.48 & -4.828 & & -1.035 \\
\hline Pricing Errors & & Mean & & Std.Dev. & & \\
\hline Small & & -0.0006 & & 5.238 & & \\
\hline$L \arg e$ & & 0.0152 & & 5.655 & & \\
\hline$G$ row $t h$ & & -0.0203 & & 5.457 & & \\
\hline Value & & 0.0042 & & 5.389 & & \\
\hline Market & & 0.0022 & & 5.526 & & \\
\hline Risk free rate & & -0.0010 & & 5.406 & & \\
\hline \multirow[t]{3}{*}{$J-s t a t$} & $\begin{array}{l}0.050 \\
(<0.01)\end{array}$ & & & & & \\
\hline & \multicolumn{6}{|c|}{ Panel B: optimal weighting matrix } \\
\hline & $c_{1}$ & $c_{2}$ & $c_{3}$ & $c_{4}$ & & $c_{5}$ \\
\hline Estimated & $\begin{array}{c}-8.566 \\
(7.578)\end{array}$ & $\begin{array}{l}77.18 \\
(63.82)\end{array}$ & $\begin{array}{l}118.5 \\
(85.45)\end{array}$ & $\begin{array}{c}-47.09 \\
(33.44)\end{array}$ & & $\begin{array}{c}-31.34 \\
(25.09)\end{array}$ \\
\hline Pr edicted & 0.124 & -10 & -30.48 & -4.828 & & -1.035 \\
\hline Pricing Errors & & Mean & & Std.Dev. & & \\
\hline Small & & 0.0398 & & 3.663 & & \\
\hline$L \arg e$ & & 0.0130 & & 3.358 & & \\
\hline$G$ row th & & 0.0074 & & 3.452 & & \\
\hline Value & & 0.0120 & & 3.364 & & \\
\hline Market & & 0.0149 & & 3.386 & & \\
\hline Risk free rate & & 0.0209 & & 3.332 & & \\
\hline \multirow[t]{3}{*}{$J-s t a t$} & $\begin{array}{l}0.436 \\
(0.509) \\
\end{array}$ & & & & & \\
\hline & \multicolumn{5}{|c|}{ " Panel C: Hansen-Jagannathan matrix } & \\
\hline & $c_{1}$ & $c_{2}$ & $c_{3}$ & $c_{4}$ & $c_{5}$ & \\
\hline Estimated & $\begin{array}{c}-5.994 \\
(5.785)\end{array}$ & $\begin{array}{l}47.93 \\
(57.05)\end{array}$ & $\begin{array}{l}91.71 \\
(65.66)\end{array}$ & $\begin{array}{c}-35.37 \\
(26.59)\end{array}$ & $\begin{array}{c}-22.62 \\
(19.41)\end{array}$ & \\
\hline Pr edicted & 0.124 & -10 & -30.48 & -4.828 & -1.035 & \\
\hline Pricing Errors & & Mean & & Std.Dev. & & \\
\hline Small & & 0.0315 & & 3.568 & & \\
\hline$L \arg e$ & & 0.0086 & & 3.347 & & \\
\hline$G$ row th & & 0.0080 & & 3.489 & & \\
\hline Value & & 0.0201 & & 3.376 & & \\
\hline Market & & 0.0119 & & 3.377 & & \\
\hline Risk free rate & & 0.0081 & & 3.200 & & \\
\hline$J-s t a t$ & $\begin{array}{l}0.550 \\
(>0.10)\end{array}$ & & & & & \\
\hline
\end{tabular}

The table reports GMM estimates of the Extended version of the LRR model. Panels A, 
$\mathrm{B}$, and $\mathrm{C}$ report results for the identity, efficient, and Hansen-Jagannathan (H-J) weighting matrices respectively. The pricing kernel is a function of the consumption growth, the log risk free rate and its lag, the log price-dividend ratio of the market and its lag, and the difference in the demeaned log dividend-consumption ratio and its lag. The asset menu consists of the market portfolio, risk free rate, the "Small", "Large", "Growth", and "Value" portfolios. The table presents the parameter estimates along with the standard errors in parentheses. Average pricing errors along with the standard deviation of the errors are presented for each asset. The bottom line in each panel reports the J-stat for overidentifying restrictions along with the p-values in parentheses. The J-stat has a non-standard aymptotic distribution for the identity and H-J weighting matrices. The $90 \%, 95 \%$, and $99 \%$ critical values for the former are $0.003,0.004$, and 0.007 , respectively, while those for the latter are 2.981, 4.052, and 7.161, respectively. For the efficient weighting matrix, the J-stat has an asymptotic $\chi^{2}-$ distribution with one degree of freedom. The data employed are annual and cover the period 1930:2006. 
Table 23: Tests of the Extended LRR Model on the 6-Asset System

\begin{tabular}{|c|c|c|c|c|c|}
\hline \multirow[b]{3}{*}{ Estimated } & \multicolumn{5}{|c|}{ Panel A: identity weighting matrix } \\
\hline & $c_{1}$ & $c_{2}$ & $c_{3}$ & $c_{4}$ & $c_{5}$ \\
\hline & $\begin{array}{c}-0.301 \\
(0.547)\end{array}$ & $\begin{array}{c}-13.64 \\
(63.13)\end{array}$ & $\begin{array}{l}-6.57 \\
(21.04)\end{array}$ & $\begin{array}{l}0.055 \\
(3.826)\end{array}$ & $\begin{array}{c}-17.35 \\
(20.03)\end{array}$ \\
\hline Predicted & 0.116 & -10.00 & 3.331 & -3.089 & -0.662 \\
\hline Pricing Errors & & Mean & & Std.Dev. & \\
\hline Small & & -0.0083 & & 1.436 & \\
\hline$L \arg e$ & & -0.0003 & & 1.585 & \\
\hline$G$ row $t h$ & & -0.0130 & & 1.547 & \\
\hline Value & & 0.0284 & & 1.544 & \\
\hline Market & & -0.0010 & & 1.580 & \\
\hline Risk free rate & & -0.0070 & & 1.518 & \\
\hline \multirow[t]{3}{*}{$J-s t a t$} & $\begin{array}{l}0.062 \\
(<0.01)\end{array}$ & & & & \\
\hline & \multicolumn{5}{|c|}{ Panel B: Hansen-Jagannathan matrix } \\
\hline & $c_{1}$ & $c_{2}$ & $c_{3}$ & $c_{4}$ & $c_{5}$ \\
\hline Estimated & $\begin{array}{c}-0.174 \\
(0.602)\end{array}$ & $\begin{array}{c}-67.34 \\
(46.41)\end{array}$ & $\begin{array}{c}-19.85 \\
(22.63)\end{array}$ & $\begin{array}{l}1.597 \\
(3.521)\end{array}$ & $\begin{array}{c}-9.019 \\
(8.450)\end{array}$ \\
\hline Predicted & 0.116 & -10.00 & 3.331 & -3.089 & -0.662 \\
\hline Pricing Errors & & Mean & & Std.Dev. & \\
\hline Small & & -0.0004 & & 1.986 & \\
\hline$L \arg e$ & & -0.0014 & & 2.073 & \\
\hline$G$ row $t h$ & & -0.0012 & & 2.038 & \\
\hline Value & & -0.0017 & & 2.026 & \\
\hline Market & & -0.0012 & & 2.065 & \\
\hline Risk free rate & & -0.0011 & & 2.387 & \\
\hline$J-s t a t$ & $\begin{array}{c}0.0026 \\
(>0.10)\end{array}$ & & & & \\
\hline
\end{tabular}

The table reports GMM estimates of the Extended version of the LRR model. Panels $\mathrm{A}$ and $\mathrm{B}$ report results for the identity and Hansen-Jagannathan (H-J) weighting matrices respectively. The pricing kernel is a function of the consumption growth, the log risk free rate and its lag, the log price-dividend ratio of the market and its lag, and the difference in the demeaned log dividend-consumption ratio and its lag. The asset menu consists of the market portfolio, risk free rate, the "Small", "Large", "Growth", and "Value" portfolios. The table presents the parameter estimates along with the standard errors in parentheses. Average pricing errors along with the standard deviation of the errors are presented for each asset. The bottom line in each panel reports the J-stat for overidentifying restrictions along with the p-values in parentheses. The J-stat has a non-standard aymptotic distribution for the identity and H-J weighting matrices. The $90 \%, 95 \%$, and $99 \%$ critical values for the former are $0.023,0.033$, and 0.057 , respectively, while those for the latter are 5.854, 7.922, and 13.40, respectively. The data employed are annual and cover the period 1947:2003. 
Table 24: Tests of the Extended LRR Model on the 6-Asset System

\begin{tabular}{|c|c|c|c|c|c|}
\hline \multirow[b]{3}{*}{ Estimated } & \multicolumn{5}{|c|}{ Panel A: identity weighting matrix } \\
\hline & $c_{1}$ & $c_{2}$ & $c_{3}$ & $c_{4}$ & $c_{5}$ \\
\hline & $\begin{array}{l}0.004 \\
(1.000)\end{array}$ & $\begin{array}{c}-10.61 \\
(41.97)\end{array}$ & $\begin{array}{c}-2.271 \\
(595.6)\end{array}$ & $\begin{array}{l}-1.229 \\
(58.69)\end{array}$ & $\begin{array}{l}0.442 \\
(38.10)\end{array}$ \\
\hline Predicted & -12.46 & -10.00 & -32.49 & -22.92 & -22.69 \\
\hline Pricing Errors & & Mean & & Std.Dev. & \\
\hline Small & & 0.0092 & & 0.228 & \\
\hline$L \arg e$ & & -0.0015 & & 0.204 & \\
\hline$G$ row th & & -0.0027 & & 0.208 & \\
\hline Value & & 0.0110 & & 0.219 & \\
\hline Market & & -0.0002 & & 0.206 & \\
\hline Risk free rate & & -0.0163 & & 0.198 & \\
\hline \multirow[t]{3}{*}{$J-s t a t$} & $\begin{array}{l}0.109 \\
(<0.01)\end{array}$ & & & & \\
\hline & \multicolumn{5}{|c|}{ Panel B: optimal weighting matrix } \\
\hline & $c_{1}$ & $c_{2}$ & $c_{3}$ & $c_{4}$ & $c_{5}$ \\
\hline Estimated & $\begin{array}{c}-0.544 \\
(1.311)\end{array}$ & $\begin{array}{c}-148.0 \\
(131.4)\end{array}$ & $\begin{array}{l}49.59 \\
(59.97)\end{array}$ & $\begin{array}{c}-3.716 \\
(3.035)\end{array}$ & $\begin{array}{c}-1.900 \\
(6.791)\end{array}$ \\
\hline Predicted & -12.46 & -10.00 & -32.49 & -22.92 & -22.69 \\
\hline Pricing Errors & & Mean & & Std.Dev. & \\
\hline Small & & 0.0021 & & 2.921 & \\
\hline$L \arg e$ & & 0.0028 & & 3.014 & \\
\hline$G$ row th & & 0.0026 & & 3.022 & \\
\hline Value & & 0.0024 & & 2.969 & \\
\hline Market & & 0.0027 & & 3.001 & \\
\hline Risk free rate & & 0.0026 & & 3.030 & \\
\hline \multirow[t]{3}{*}{$J-s t a t$} & $\begin{array}{l}0.022 \\
(0.881) \\
\end{array}$ & & & & \\
\hline & \multicolumn{5}{|c|}{ Panel $C:$ Hansen-Jagannathan matrix } \\
\hline & $c_{1}$ & $c_{2}$ & $c_{3}$ & $c_{4}$ & $c_{5}$ \\
\hline Estimated & $\begin{array}{l}-0.555 \\
(1.402)\end{array}$ & $\begin{array}{c}-148.0 \\
(135.6)\end{array}$ & $\begin{array}{l}49.58 \\
(63.03)\end{array}$ & $\begin{array}{c}-3.757 \\
(3.080)\end{array}$ & $\begin{array}{c}-2.000 \\
(7.373)\end{array}$ \\
\hline Predicted & -12.46 & -10.00 & -32.49 & -22.92 & -22.69 \\
\hline Pricing Errors & & Mean & & Std.Dev. & \\
\hline Small & & $-3.7 \times 10^{-}$ & & 2.932 & \\
\hline$L \arg e$ & & $4.6 \times 10^{-4}$ & & 3.024 & \\
\hline$G$ row $t h$ & & $1.8 \times 10^{-4}$ & & 3.032 & \\
\hline Value & & $3.4 \times 10^{-4}$ & & 2.983 & \\
\hline Market & & $3.4 \times 10^{-4}$ & & 3.011 & \\
\hline Risk free rate & & $5.1 \times 10^{-4}$ & & 3.041 & \\
\hline$J-s t a t$ & $\begin{array}{l}0.025 \\
(>0.10)\end{array}$ & & & & \\
\hline
\end{tabular}

The table reports GMM estimates of the Extended version of the LRR model. Panels A, 
$\mathrm{B}$, and $\mathrm{C}$ report results for the identity, efficient, and Hansen-Jagannathan (H-J) weighting matrices respectively. The pricing kernel is a function of the consumption growth, the log risk free rate and its lag, the log price-dividend ratio of the market and its lag, and the difference in the demeaned log dividend-consumption ratio and its lag. The asset menu consists of the market portfolio, risk free rate, the "Small", "Large", "Growth", and "Value" portfolios. The table presents the parameter estimates along with the standard errors in parentheses. Average pricing errors along with the standard deviation of the errors are presented for each asset. The bottom line in each panel reports the J-stat for overidentifying restrictions along with the p-values in parentheses. The J-stat has a non-standard aymptotic distribution for the identity and H-J weighting matrices. The $90 \%, 95 \%$, and $99 \%$ critical values for the former are $0.0015,0.0021$, and 0.0036, respectively, while those for the latter are 3.633, 5.500, and 8.808, respectively. For the efficient weighting matrix, the J-stat has an asymptotic $\chi^{2}$-distribution with one degree of freedom. The data employed are quarterly and cover the period 1947:3-2003:3. 